Research Article

\title{
Dynamic Characteristics of the Surrounding Soil during the Vibrational Pulling Process of a Pile Based on DEM
}

\author{
Tingting Sun, ${ }^{1}$ Zhihua Zhang $\mathbb{D}^{2},{ }^{2}$ Jixin Yang $\mathbb{D},{ }^{1}$ Jingnan Yang, ${ }^{1}$ and Xuan Zhang ${ }^{1}$ \\ ${ }^{1}$ School of Transportation, Wuhan University of Technology, Hubei, Wuhan 430063, China \\ ${ }^{2}$ Changjiang River Scientific Research Institute of Changjiang Water Resources Commission, Hubei, Wuhan 430010, China
}

Correspondence should be addressed to Zhihua Zhang; zzh@whut.edu.cn and Jixin Yang; whutvses@163.com

Received 10 September 2019; Revised 17 January 2020; Accepted 6 February 2020; Published 12 March 2020

Academic Editor: Yuri S. Karinski

Copyright (C) 2020 Tingting Sun et al. This is an open access article distributed under the Creative Commons Attribution License, which permits unrestricted use, distribution, and reproduction in any medium, provided the original work is properly cited.

When bridge construction has been completed, the temporary support system, such as a steel-pipe pile, is dismantled, and problems that are related to the steel-pipe piles pulling from the strata are encountered. It is difficult to measure the dynamic characteristics of the surroundings during the deep pile-pulling process. A numerical model of the pulling pile is established by using the discrete element method (DEM). A sinusoidal dynamic load is executed on the pile with various vibrational frequencies. The stress, bond, coordination number, porosity, and velocity field distribution of the surrounding soil during the pile-pulling process are studied. The results demonstrate that, during the pile-pulling process, the shearing state of the surrounding soil depends on the position of the pile. The number and area of bond fractures gradually increase, the coordination number decreases, and the porosity gradually increases when the pile-pulling distance increases. Under a vibrational load, the area that corresponds to particles with large velocity and displacement expands with the increase of the vibrational frequency. The major influence zone of the pile pulling on both sides is concentrated within $6 \mathrm{~d}_{\text {pile, }}$, which can be used to evaluate the safety of the existing bridge nearby during pile pulling.

\section{Introduction}

During bridge construction, steel-pipe piles are used as a temporary support system for bearing various construction loads. After bridge construction has been completed, the temporary support system is dismantled, which results in problems related to the drawing of steel-pipe piles from the strata, especially relatively deep steel-pipe piles. Meanwhile, to better reflect the resource-saving and environment-friendly concept, the pulled-out steel-pipe pile can also be reused. However, it is difficult to measure the dynamic properties of the surrounding soil and the impact of the pile-pulling process on-site. To evaluate the influence area around the pile during the pulling process, it is necessary to study the interaction between the soil and the pile during the pulling process.

In recent years, the axially loaded piles have attracted attention of many scholars. For axially loaded piles, various methods have been used, including field tests [1-3] and laboratory tests [4-7]. For the field tests, Zhang et al. [8] examined the influence of the press pile on material strength, which can have positive impact on mobilizing the shaft resistance [9]. Comparing field tests with laboratory tests, the field tests are rather complicated and the laboratory tests are relatively simple. Therefore, many researchers used laboratory tests to analyze the relationship of pile-soil. Ghalesari et al. [10] investigated the settlement behavior of a large piled raft and found that the soil, pile configurations, and different sizes have a significant effect on the settlement behavior. The three-dimensional finite element model and loaded pile tests were also carried out by Ghalesari and Rasouli [11] who found that the gravel layer thickness and grain size affected the foundation and the settlement behaviors of the pile and the pile-soil contact interface were similar to the experimental results and calculation results [12-14]. A series of model tests of pile foundations were performed to investigate the dynamic responses of the open-ended pipe pile under lateral cyclic loadings, and the test results showed that the resistance of each part of the pipe pile increases linearly with depth during the process of pile driving [15].

Because of the lack of literature for pile pulling, the theoretical basis of the press pile and uplift piles can be applied for 
reference. For the uplift piles, Krishna and Patra [16] performed model tests on the uplift loads for the bearing capacity of a single pile in tight sandstone. The experimental results demonstrated that the net uplift capacity decreases with the increase in percentage of the compressive loads [4]. Rahman and Sengupta [6] compared various pile diameters with different inclination angles via experiments and obtained ultimate uplift loads with sand grains of different densities. Azizkandi et al. [17] proposed an artificial neural network model to analyze the displacement of uplift piles and found that, under the action of loads, uplift displacement might occur. Foundation systems are important structures that require uplift resistance [18] hence, the induced displacement of uplift pile is a disadvantage for structures. Many factors affect the uplift pile foundation, such as the length, diameter [19], embedment ratio [20], and soil types of piles [4]. Piles are frequently used to transfer loads to strong soil layers [13]. Therefore, the bearing capacity of the soil has a great influence on the pile foundation, especially the vibration that is generated by an earthquake [21]. When an earthquake occurs, soft soils may be subjected to disfiguration [22], which can reduce the serviceability of the structure; meanwhile, the pile displacement accumulation [23] may result in damage to existing piles [5]. The pulling pile is quite different from the uplift pile that an uplift pile limits the displacement of the pile [17], whereas the pulling pile is to pull the pile out from the strata completely. Therefore, the evaluation of the dynamic interaction between the pile and the soil is significant.

However, it is a challenge to identify the dynamic characteristics of the surrounding soil during the pilepulling process in the field and laboratory tests. Numerical models can be used to find the dynamic characteristics of the soil by observing the micromechanical collision and motion of individual particles. Based on this microscopic observation, the variations of the stress, bond, coordination number, porosity, and velocity field distribution during the pilepulling process can be quantified.

In the past few decades, the discrete element method (DEM) has been extremely useful for calculating rock and soil mechanics [24]. Aside from laboratory tests and field tests, numerical simulations are pivotal for investigating the actions of granular flows that interact with constructions [25]. For the DEM, Chen et al. [26] conducted a particle flow code in two-dimensional (PFC2D) model to simulate piles, and a comparison of the numerical and experimental results demonstrated the applicability of this approach. During the pulling process, the surrounding soil may be fluidized. Hence, Zhang et al. [27] used a 2D DEM model to analyze the fluidization of soil particles during vibrational shearing in direct shear tests. Ma et al. [28] adopted the DEM to calculate the dynamic compaction process of soil. In addition, the DEM can identify macroscopic and microscopic mechanisms of soils during dynamic compaction [29]. Fu et al. [30] presented discrete element modeling to reveal the micromechanisms and macrobehaviors of the installation responses of rigid open-ended piles with different diameters $(22.5,45$, and $90 \mathrm{~mm})$. Meanwhile, Liu et al. [31] revealed the load transfer processes of the open-ended piles. Currently, there are few discussions on the adoption of the discrete element method and on the effect on the pile-soil dynamic properties during the pile-pulling process.

In this paper, a pile-pulling model is proposed by using the DEM, and the pile assembled by the clump is pulled from the surrounding soil of clay with a sinusoidal dynamic load with different frequencies. The main purpose of this paper is to study the dynamic characteristics of the surrounding soil during the pile-pulling process. The novelty of this work is to determine the influence of the surrounding area during the pile-pulling process by using numerical simulation as a technical reference for bridge construction on-site. In order to evaluate the influence area, the dynamic responses of the surrounding soil, such as the distribution of the stress, bond, coordination number, porosity, and velocity field, are analyzed during various pile-pulling distances.

\section{Project Information of Jianning Bridge}

This paper considers the pile-pulling project of Jianning Bridge as the research object. Jianning Bridge is located in Shishou City, Hubei Province, China. The total length of the bridge is $548 \mathrm{~m}$, and the cross section of the main girder is $45.8 \mathrm{~m}$. The temporary support system is composed of bailey beams and steel-pipe piles. There are 252 steel-pipe piles, all of which must be pulled out. This paper uses the deepest steel-pipe pile as the research object. The geological conditions of the pile are as follows: the mountain lake has a water depth of 1-2 $\mathrm{m}$ and no flow velocity. The depth range of the exploration covers the geology from the surface of the clay (greater than $30 \mathrm{~m}$ ), the longest depth of penetration is $26 \mathrm{~m}$, and the pile body is mainly in the clay layer. The pilesoil distribution is shown in Figure 1.

\section{Numerical Simulation}

3.1. Discrete Element Method. The DEM was first proposed by Cundall and Strack [32]. The main calculation strategy of this method is to use discrete particles to simulate the interactions between rigid spheres [33]. This method can be used in geotechnical engineering [25, 34-36], load transfer mechanism [31], soil failure [37, 38], failure mechanism [39], micromechanisms [30], high-speed train operation [9], metro train operation [40, 41], fluidization [27], particle migration [42], strain softening [43], and filling capacity of concrete [44].

3.2. Model Hypotheses. The pile to be pulled is located in the river, and the pile is set in the water. The model of this paper mainly considers the deepest pile to be pulled. The following assumptions are made during the construction of the model:

(1) As reported by Zhang and Sun [45], the permeability could be neglected because the initial seepage field was evenly distributed in the engineering area. Water infiltration is overlooked due to the low permeability of the clay and steel-pipe pile.

(2) The buoyancy force is determined on the basis of Archimedes' principle [46], which is suitable for structures in granular materials (e.g., sand). However, for the structures in cohesive soil, a reduction 


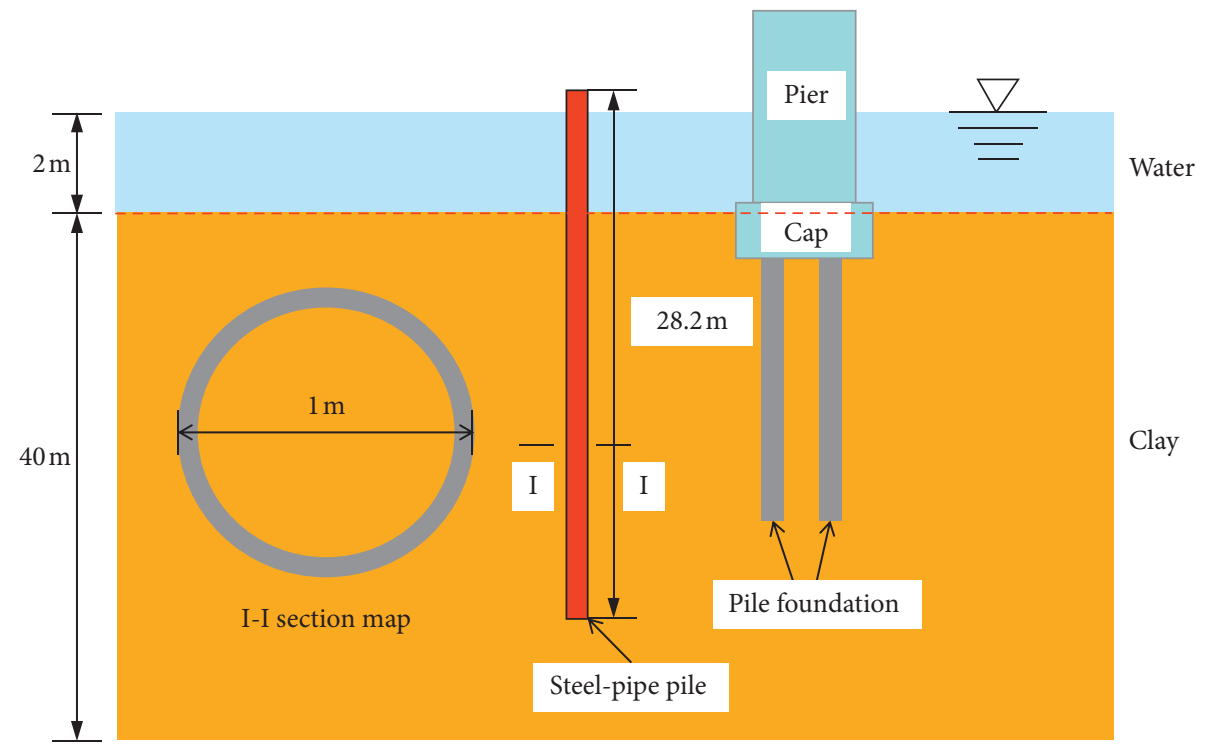

FIGURE 1: Schematic diagram of the pile-soil distribution.

coefficient of buoyancy force should be considered. Song et al. [47] and $\mathrm{Ni}$ et al. [48] conducted the force equilibrium of the model box under different loading conditions and found that the buoyancy force reduction coefficient was $73 \%$ which was smaller than the theoretical water buoyancy force calculated by using Archimedes' principle in saturated clayey soils. Therefore, in the present model, the reduction coefficient of buoyancy force is determined to be 0.73 .

$$
F_{p}=0.73 \rho g V_{p}
$$

where $V_{p}$ is the particle volume [47].

(3) The pile is modeled by using a clump [33] that has strong stiffness and strength, and the deformation and stress of the pile to be pulled under the load are not considered during the pulling process.

(4) The lateral earth pressure increases with the depth because the wall in the model is a rigid surface and the height of the model is $40 \mathrm{~m}$. The average pressure is used to calculate the lateral pressure in the model [8].

(5) The limitations of the 2D DEM have been highlighted, which are due to the neglect of the momentum transfer in the lateral direction [49]. Fortunately, the main advantage of $2 \mathrm{D}$ is the reduced number of elements and reduced calculation time [25].

3.3. Microparameter Calibration of Soil. In general, the selection of an appropriate set of microproperties is a requirement step in DEM simulation [50]. In this study, the direct shear tests of clay are conducted. Particle-size distribution curves of the samples used in the laboratory and DEM are shown in Figure 2(a). In the experimental study, a series of direct shear tests are conducted with different normal stresses of 100,200 , and $300 \mathrm{kPa}$. The size of the experimental specimen is $61.8 \mathrm{~mm} \times 20 \mathrm{~mm}$ (length $\times$ height), and the testing procedure follows [51].
For the microparameter calibration, Young's modulus and the cohesive bond obtained in the laboratory can be directly applied in the direct shear simulations, whereas the other microparameters such as particle stiffness, stiffness ratio (normal to tangential stiffness), and friction coefficient should be calibrated from a series of simulations [40]. The numerical model is assembled by using the PFC2D with the same size in the laboratory. The limitations of $2 \mathrm{D}$ analysis were measured by Cui et al. [25] that the particles could only move in the plane direction, but they could capture the main shearing characteristics of the material and improve the calculation efficiency. The assembled particles and the numerical walls are shown in Figure 2(b). The upper half of the box (wall numbers 1,2, and 3) is displaced to the right at a constant velocity of $0.06 \mathrm{~mm} / \mathrm{min}$ which is consistent with that in the laboratory. The comparison of the DEM and laboratory results after calibration is shown in Figure 2(c). As shown in Figure 2(c), the numerical results are near perfect consistent with the laboratory results.

However, the radii of particles used in the calibration model are relatively smaller than those in the large pilepulling model which will decrease the calculation efficiency. In order to balance the particle-size effect and the calculation efficiency, the particle size used in the pile-pulling model should be enlarged. Several literature studies have focused on the particle-size effect: Lu et al. [52] conducted the triaxial tests by using the DEM in numerical simulation, and the minimum size of particles in their model was $5 \mathrm{~mm}$ which was larger than the original value of $0.075 \mathrm{~mm}$. Gu et al. [53] analyzed the particle-size effect in numerical simulation and found that the particle scale effect could be possibly avoided when the ratio of the sample size to the mean particle size is larger than 11.5. Referring to Zhang et al. [8], the particle size is set to be $0.06-0.10 \mathrm{~m}$ in the pile-pulling model to increase the time efficiency, and the ratio of the sample size to the mean particle size is approximately 500 which is larger than 11.5. Therefore, the input microparameters for the pilepulling numerical simulation are shown in Figure 2. 


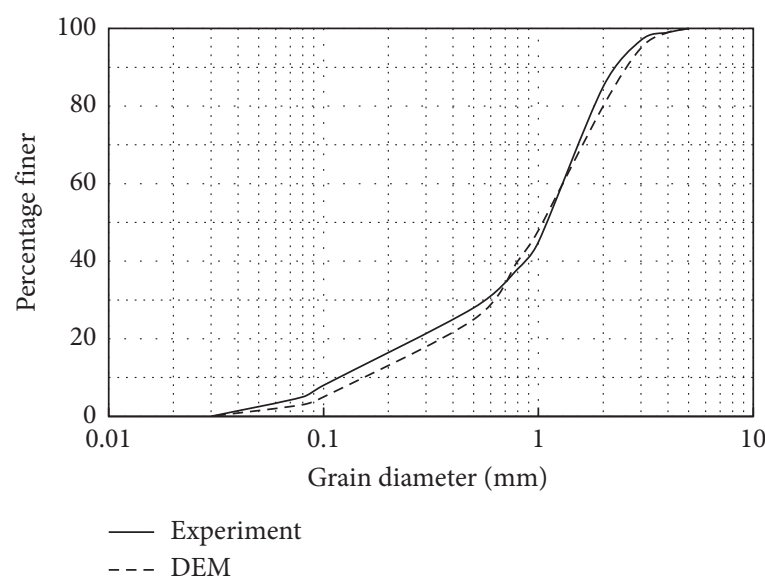

(a)

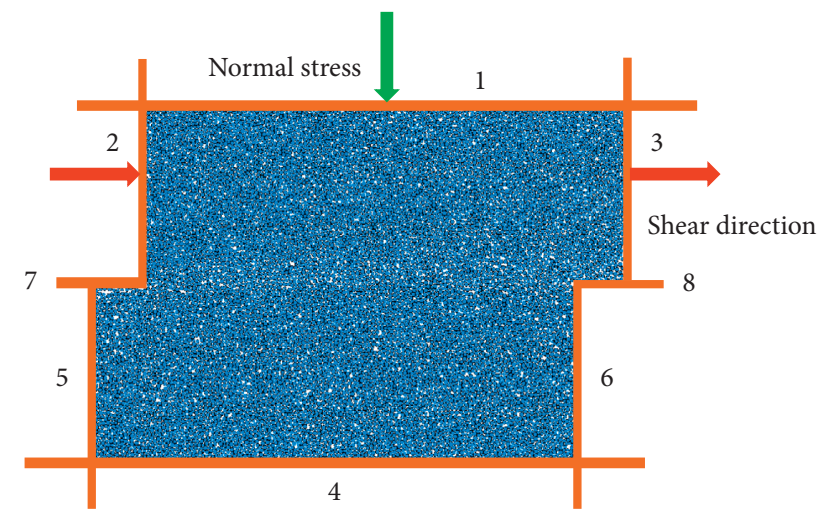

(b)

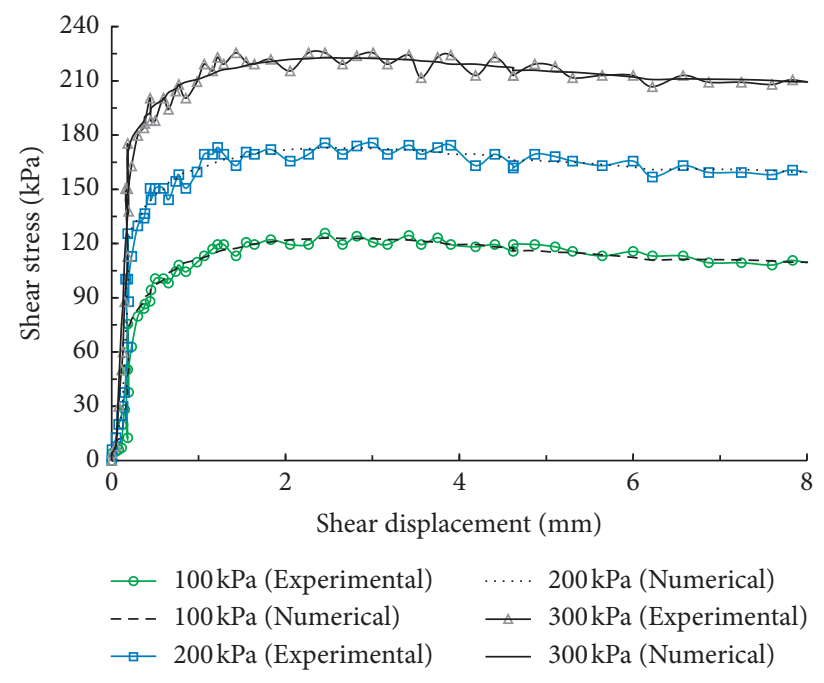

(c)

Figure 2: (a) Particle-size distribution of the experiment and DEM; (b) direct shear test of the DEM model; (c) microparameter calibration of soil.

3.4. Microparameter Calibration of Pile. Before the modeled pile is used in the pile-pulling model, several microparameters of the pile should be calibrated, such as the normal stiffness of particles, the pile friction coefficient at the boundary, the normal stiffness of the bond, the bond radius multiplier, and the tensile strength.

For the pile modeling, Zhan et al. [54] used the clump and parallel-bond model to generate pile foundation models of different pile diameters and studied the press pile mechanism. Sadrmanesh and Chen [55] reported a new approach to simulate the tensile strength of the pile by the DEM. In order to determine the microparameters of the pile used in the present model, the numerical tensile tests are conducted.

The pile is assembled by clumps as a disk with a width $\times$ height of $1 \mathrm{~m} \times 2 \mathrm{~m}$. In the present model, the dynamic movement of the pile is associated with time which is controlled by time-stepping. The time-stepping is calculated by the particle mass and the particle stiffness that if the particle is small enough, the pile generated by the particles will move slowly which can decrease the calculation efficiency. Therefore, three particle sizes of $0.01,0.05$, and $0.10 \mathrm{~m}$ for generating the pile are used to characterize the particle-size influence on the tensile strength of the pile, as shown in Figure 3(a). The extension velocity is $1 \mathrm{~mm} / \mathrm{s}$ [56]. The tensile stress versus strain curves with different particle sizes are shown in Figure 3(b). As shown in Figure 3(b), the particle size has little influence on the tensile strength of pile, and the tensile strength is approximately $350 \mathrm{MPa}$, which is almost consistent with the tensile strength of the steel-pipe pile of Q345. Therefore, in order to improve the calculation efficiency, the particle size for generating the modeled pile is selected to be $0.05 \mathrm{~m}$. The input microparameters of the pile are listed in Table 1.

3.5. Vibrational Load. The DZJ-400 vibration hammer parameters are selected in the actual construction, which are listed in Table 2.

The DZJ-400 vibration hammer is used to pull out the pile that can provide different excitation force $(0-3184 \mathrm{kN})$ and 10 to 50 different frequencies (low frequency $0-15 \mathrm{~Hz}$, intermediate frequency $15-25 \mathrm{~Hz}$, and high frequency 25-50 Hz). In the construction plan of Jianning Bridge prepared by China First Metallurgical Group Co., Ltd. [57] 


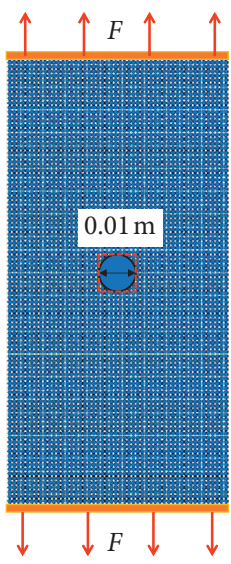

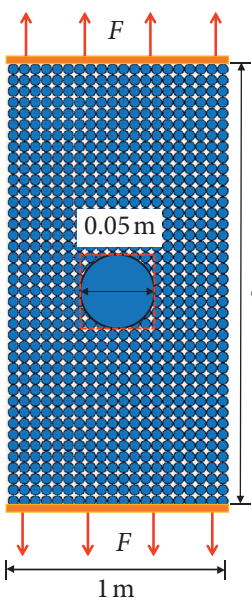

(a)
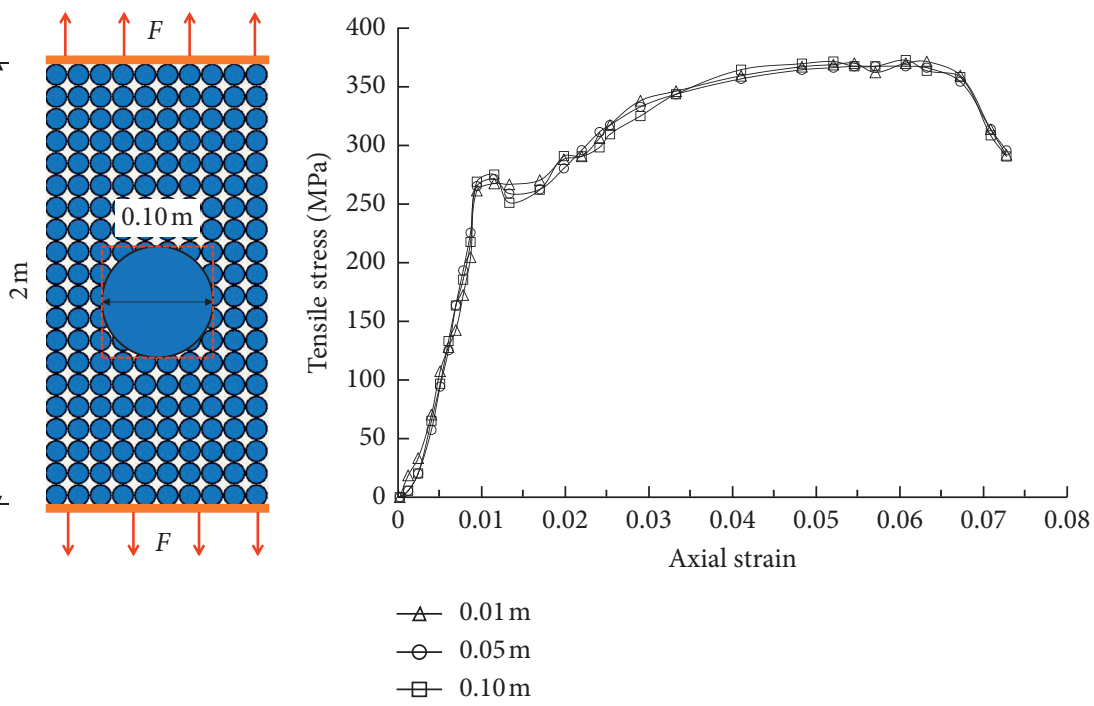

(b)

Figure 3: Microparameter calibration of the pile: (a) different-sized DEM models of the pile; (b) stress-strain curves in tension.

TABLE 1: Micro/macroparameters used in the pile-pulling model.

\begin{tabular}{lcc}
\hline Parameter (unit) & Clay & Clump \\
Diameter $(\mathrm{m})$ & $0.06-0.10$ & 0.05 \\
Density $\left(\mathrm{kg} / \mathrm{m}^{3}\right)$ & 1700 & 2400 \\
Normal stiffness $(\mathrm{N} / \mathrm{m})$ & $1.2 \times 10^{7}$ & $5.0 \times 10^{9}$ \\
Shear stiffness $(\mathrm{N} / \mathrm{m})$ & $1.2 \times 10^{7}$ & $5.0 \times 10^{9}$ \\
Friction coefficient & 0.55 & 1.50 \\
Normal strength of the contact bond $(\mathrm{Pa})$ & $2.50 \times 10^{4}$ & - \\
Shear strength of the contact bond $(\mathrm{Pa})$ & $2.50 \times 10^{4}$ & - \\
Normal stiffness of the parallel bond $(\mathrm{N} / \mathrm{m})$ & - & $9.20 \times 10^{9}$ \\
Shear stiffness of the parallel bond $(\mathrm{N} / \mathrm{m})$ & - & $9.20 \times 10^{9}$ \\
Normal strength of the parallel bond $(\mathrm{Pa})$ & - & $1.00 \times 10^{8}$ \\
Shear strength of the parallel bond $(\mathrm{Pa})$ & - & $1.00 \times 10^{8}$ \\
Parallel bond radius multiplier & - & 1.00 \\
\hline
\end{tabular}

of Hubei Branch, the DZJ-400 vibration hammer was used in the field of pile pulling, with a vibration frequency range of $10-50 \mathrm{~Hz}$ and a maximum excitation force of $3000 \mathrm{kN}$.

The pulling force $F$ during the pulling process is expressed as follows:

$$
F=F_{1}+F_{2} \sin (2 \pi f t)
$$

where $F_{1}$ is the pile weight, $F_{2}$ is the exciting force, $f$ is the vibrational frequency, and $t$ is time. In the calculation, $F_{1}$ is $100 \mathrm{kN}$ (pile self-weight and soil plug) and $F_{2}$ is $3000 \mathrm{kN}$.

Therefore, this paper used the parameters of the DZJ-400 vibration hammer to simulate vibrational loads, with the maximum exciting force of $3000 \mathrm{kN}$ and different frequencies of 10,20,30, 40, and $50 \mathrm{~Hz}$.

3.6. Whole Model. In this model, the soil particle size ranged from 0.06 to $0.10 \mathrm{~m}$, the model size was $40 \times 50 \mathrm{~m}$ (height $\times$ width), and a total of 68,051 particles were simulated. The numerical simulation modeling in this paper is mainly divided into the following steps:
Step 1: to guarantee a tight initial packing, the particles utilized a model that was produced via the gravitational deposition method. A population of particles of various diameters was created according to the specifications and placed in a box until the box was full. Clay was considered for building the entire particle model.

Step 2: the servomechanism was used to compact the particles and to realize a design compressive stress of $1 \mathrm{kPa}$ in the box [8].

Step 3: the ball particles at the position of the pile were deleted, and the clump was used to generate the pile model. The clump was formed by 2,701 balls [33]. The diameter of the pile was $1 \mathrm{~m}$, and the length was $28.2 \mathrm{~m}$. The clump parameters are listed in Table 1. To realize sufficient interaction between the pile and the surrounding soil, several cycles were executed to put the model in a quasistatic state.

Step 4: a sinusoidal load was applied to the clump, and various frequencies were considered.

In the PFC, the measurement circles can measure the magnitude of the stress within the specified zone [58]. A total of 2000 measurement circles are set in the model along the horizontal and vertical directions; each measurement circle has a diameter of $1 \mathrm{~m}$, contains approximately 100 particles, and covers the entire model area. The pile-soil diagram is shown in Figure 4, and the measurement circle layout is shown in Figure 5.

\section{Numerical Simulation Results}

Based on the construction of the numerical model, a dynamic vibrational load is applied on the pile with the clumping property. Vibrational frequencies of 10, 20,30, 40, and $50 \mathrm{~Hz}$ are considered with the same excitation force of $3000 \mathrm{kN}$ for evaluating the frequency effect. The stress, bond 
TABle 2: Parameters of the DZJ-400 vibration hammer.

\begin{tabular}{lccccccc}
\hline $\begin{array}{l}\text { Power } \\
(\mathrm{kW})\end{array}$ & $\begin{array}{c}\text { Eccentric moment } \\
(\mathrm{N} * \mathrm{~m})\end{array}$ & $\begin{array}{c}\text { Exciting force } \\
(\mathrm{kN})\end{array}$ & $\begin{array}{c}\text { Amplitude } \\
(\mathrm{mm})\end{array}$ & $\begin{array}{c}\text { Low frequency } \\
(\mathrm{Hz})\end{array}$ & $\begin{array}{c}\text { Intermediate frequency } \\
(\mathrm{Hz})\end{array}$ & $\begin{array}{c}\text { High frequency } \\
(\mathrm{Hz})\end{array}$ \\
400 & 4766 & $0-3184$ & $0-18.2$ & $0-15$ & $15-25$ & $25-50$ \\
\hline
\end{tabular}

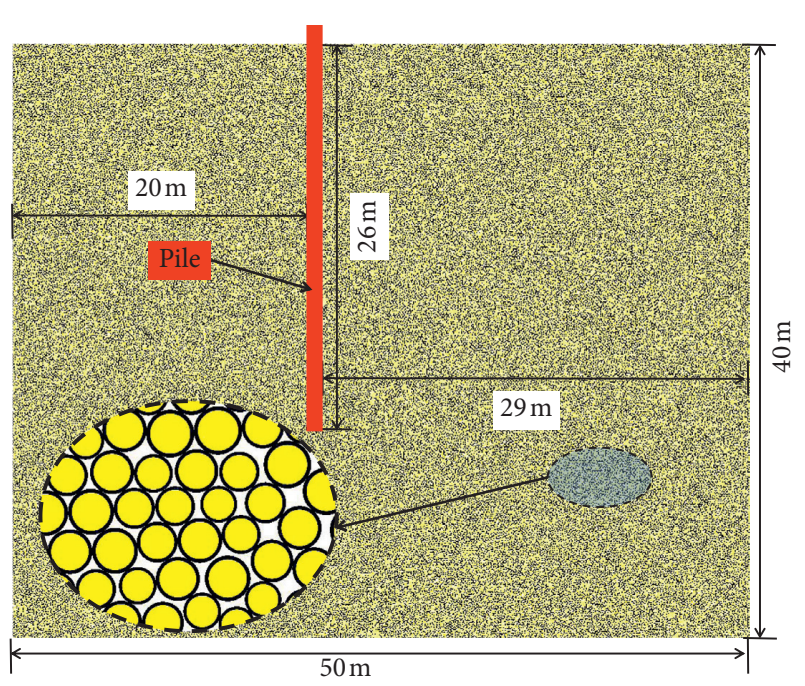

Figure 4: Pile-soil diagram.

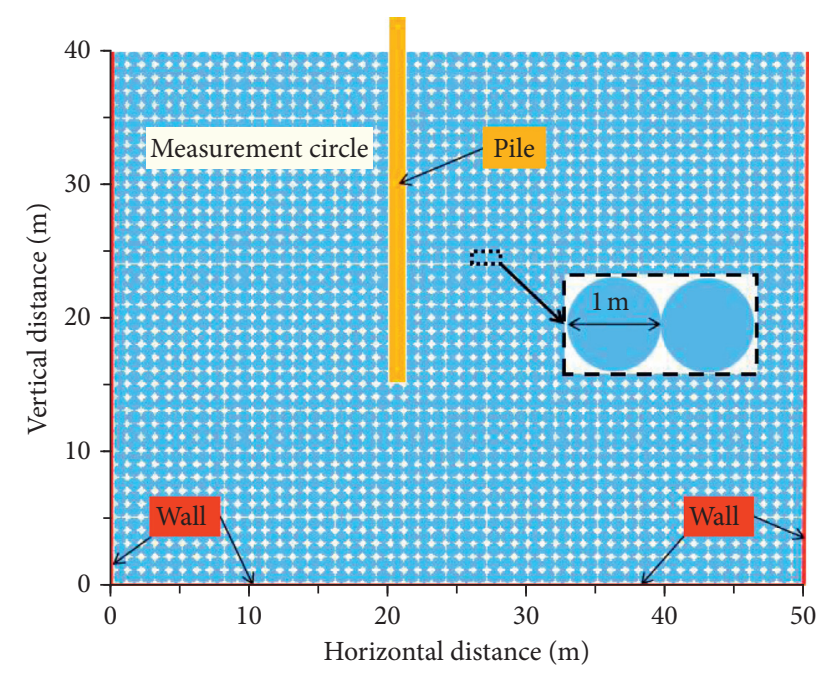

FIGURE 5: Layout of the measurement circles.

distribution, coordination number, porosity, and velocity field of the surrounding soil are analyzed during the pilepulling process with pulling distances of $1,2,3,4$, and $5 \mathrm{~m}$.

4.1. Stress Variation. Three measurement circles are arranged at the top, the middle, and the bottom of the pile to analyze the stress variation of the soil particles during the pulling process. The relationships between the stress in the vertical direction and the pile-pulling time at various positions are presented in Figure 6.

As shown in Figure 6, soil particles at different positions of the pile are shearing at different states. Particles at the top and the middle sides of the pile are shearing in the critical state in which there is little shear stress except for a few sharp peaks, as shown in Figures 6(a) and 6(b). Based on the sharp peaks and the zero point of the stress, the particles are separating from the assembly and reassembling together with large contact forces [40]. The particles at the bottom of the pile are shearing prior to the critical state because their shear stress increases with the shear displacement, which is represented by the pulling distance. In order to analyze the stress variation of the surrounding soil more comprehensively, 10 measurement circles are arranged on both sides of the pile, and the stress curve distribution versus pile-pulling distance is shown in Figure 7.

Before pulling the pile, the stress of the whole pile-pulling model has been monitored by the measurement circles (Figure 5). In Figure 7, five stages of pile-pulling distances of 1.0, $2.0,3.0,4.0$, and $5.0 \mathrm{~m}$ are selected for analyzing the variation of vertical stress of the surrounding soil. For the vertical stress, as shown in Figure 7, the stress variations of the particles along the pile during the pulling process are in good agreement with the results in Figure 6 when the pulling distance is less than $1.0 \mathrm{~m}$. During the pulling process, the surrounding soil of the pile shears at the critical state after the pulling distance exceeds $1.0 \mathrm{~m}$ (Figures $7(\mathrm{a})-7(\mathrm{~h})$ ), except for the soil at the top of the pile (Figures 7(i) and 7(j)). To further investigate the stress variations of granular soil during the pulling process, two peaks of shear strength occur at the middle of the surroundings with pulling distances of $1 \mathrm{~m}$ and $3 \mathrm{~m}$, as shown in Figures 7(e) and $7(f)$. The soil reaches the peak shear strength, the soil particles are separated and reassembled, and the rearranged assembly is shearing to attain a larger shear strength, as shown in Figure 7(e). However, in Figures 7(i) and 7(j), the shear stresses become relatively small during the pulling process due to the lateral earth pressure at the top of the pile being much smaller and the soil particle shearing entering a critical state at a larger shearing distance. As shown in Figure 7, the vertical stresses increase with the vibrational frequency because of the vibration that is caused by repacking [27].

4.2. Bond Fractures. For the research of the vibrating pile, most scholars considered different vibration frequencies and conducted a lot of research. Henke and Grabe [59] chose the driving frequency $(30 \mathrm{~Hz})$ for simulation of vibrational pile driving which was controlled by applied forces. To avoid resonance in the ground structural elements causing damage, the vibration frequency was also set to be $30 \mathrm{~Hz}$ by Adejumo and Boiko [60]. Kitovas et al. [61] carried out the vibrational direct shear tests under static loads with vibrational frequencies of 10,30 , and $50 \mathrm{~Hz}$, and the experiments showed that cohesion of clay decreased under vibrations of $30 \mathrm{~Hz}$ frequency. Choudhary et al. [62] studied the dynamic responses of the 3-pile group by conducting vertical vibration tests for different excitation intensities $(20,30$, and $40 \mathrm{~Hz}$ ) under the static load of $10 \mathrm{kN}$, which verified the applicability of the theoretical formulations based on the 


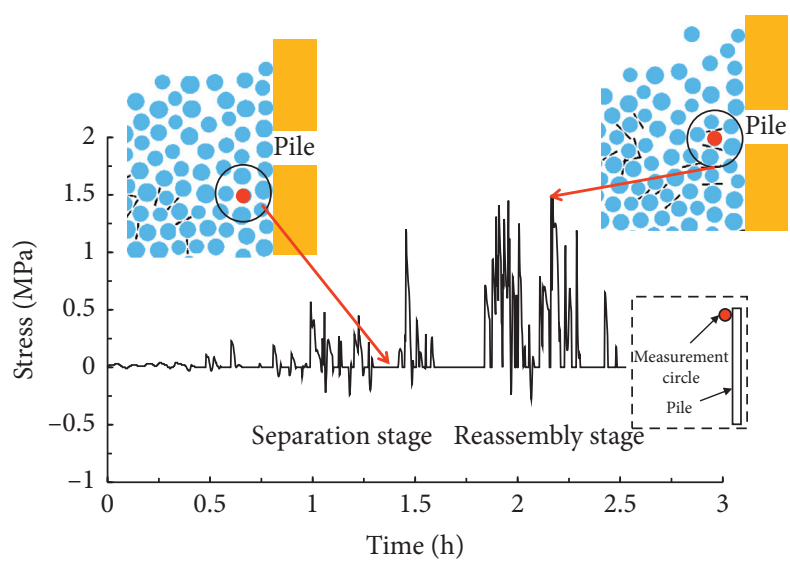

(a)

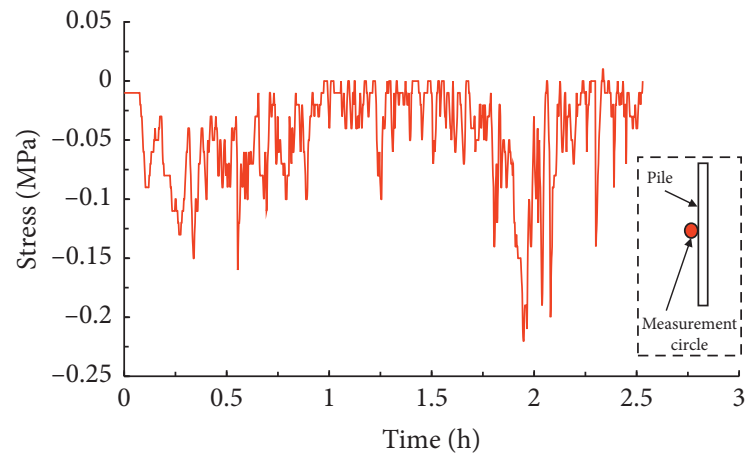

(b)

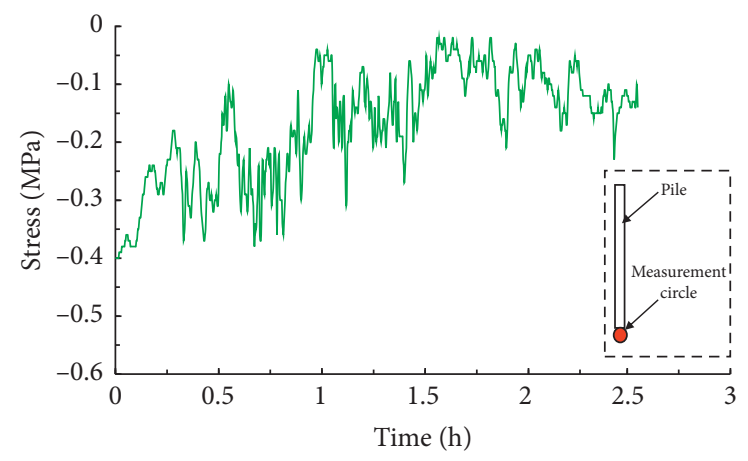

(c)

FIgURE 6: Pile-side stress change at the (a) top, (b) middle, and (c) bottom.

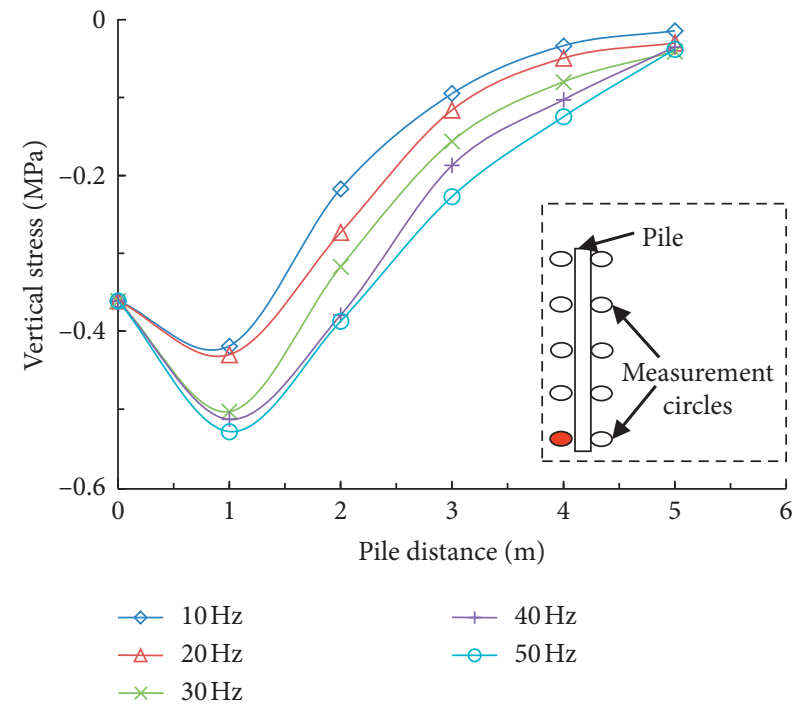

(a)

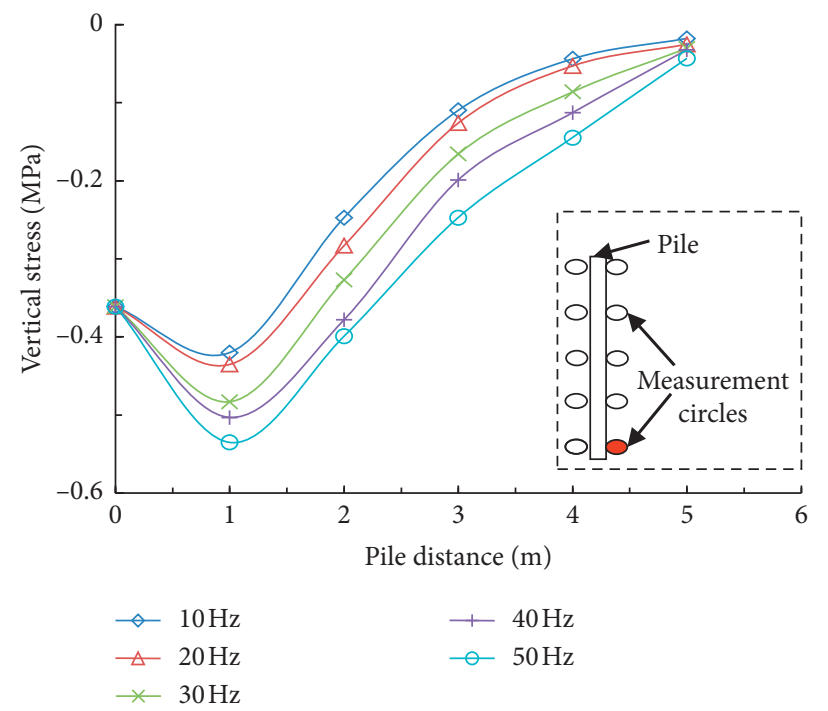

(b)

Figure 7: Continued. 

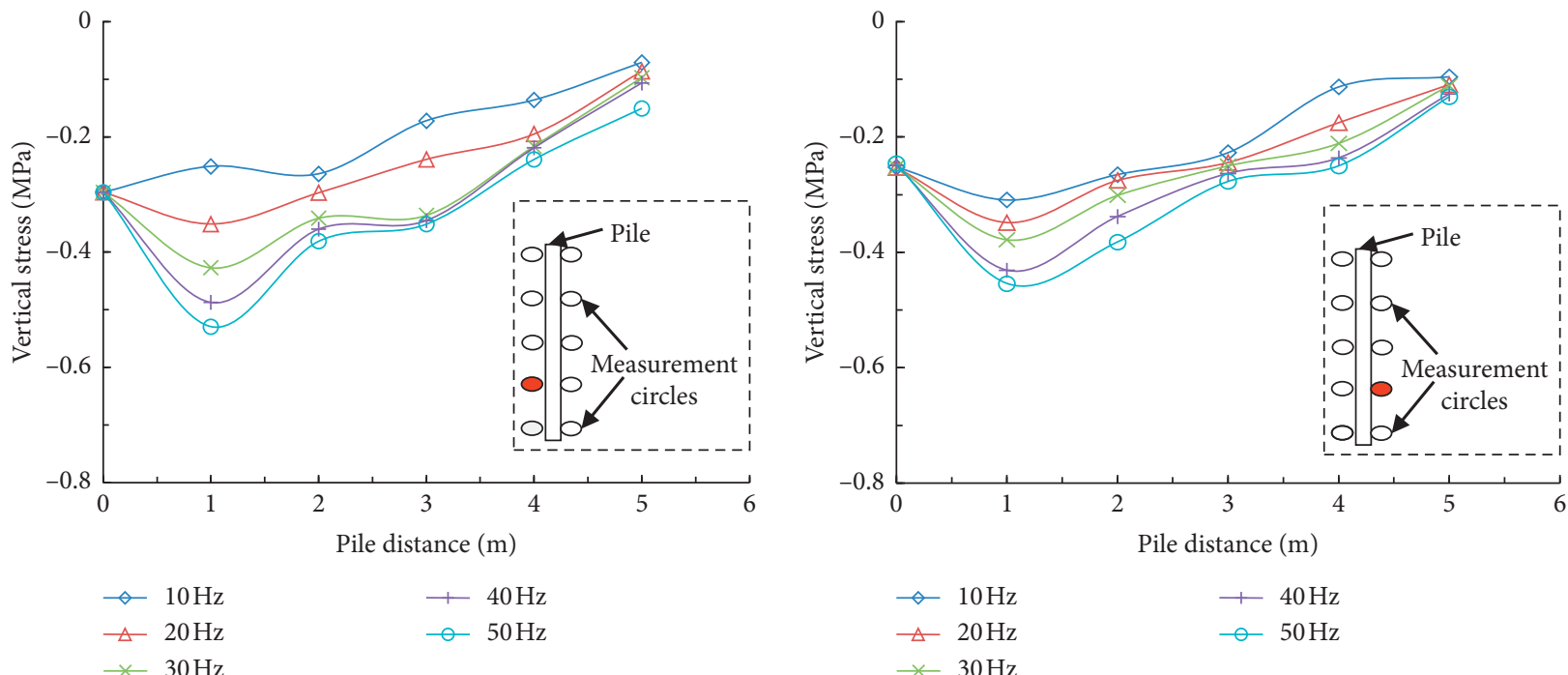

(c)

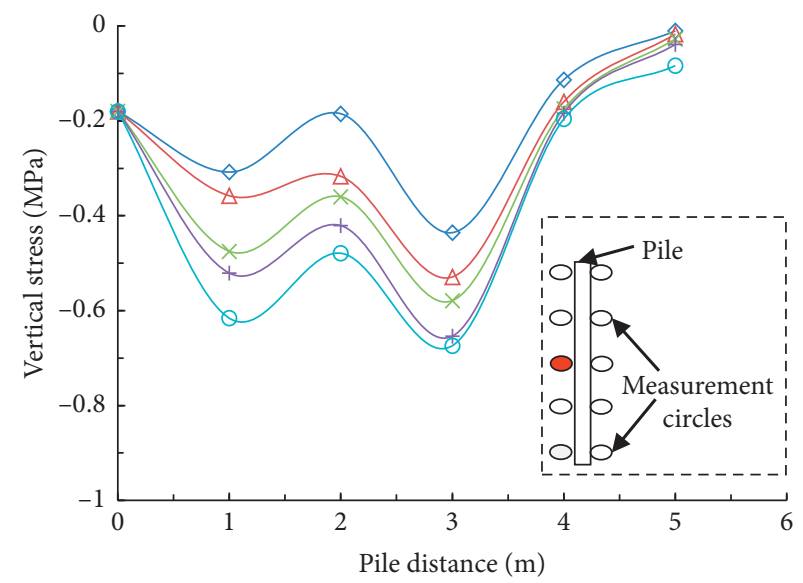

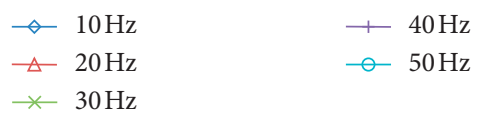

(e)

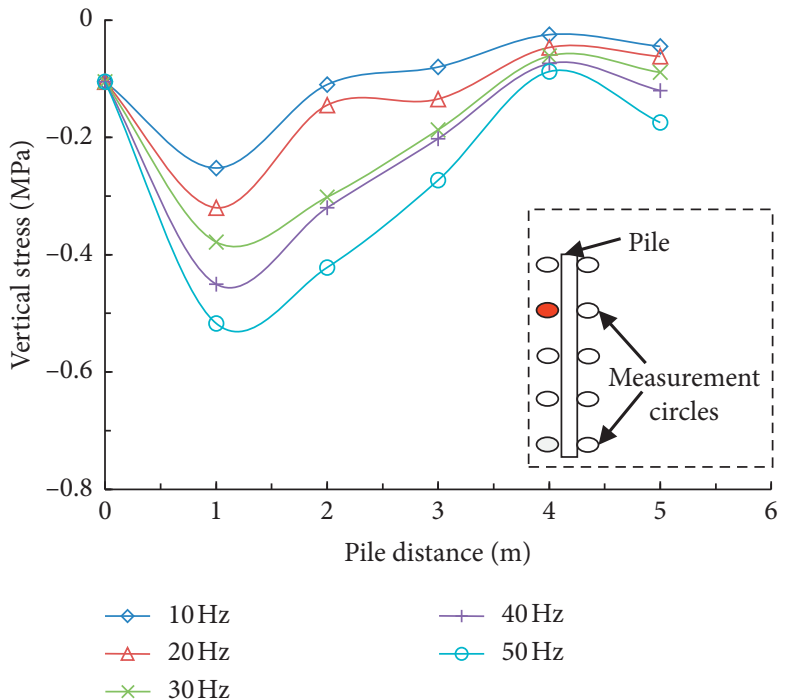

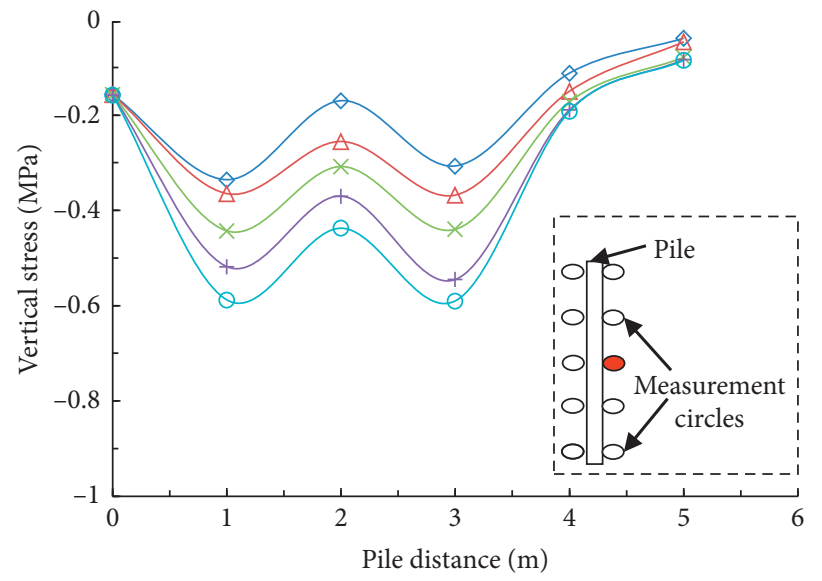

(d)

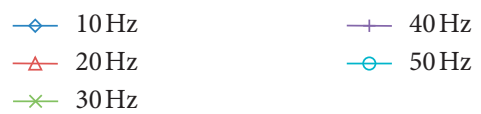

(f)

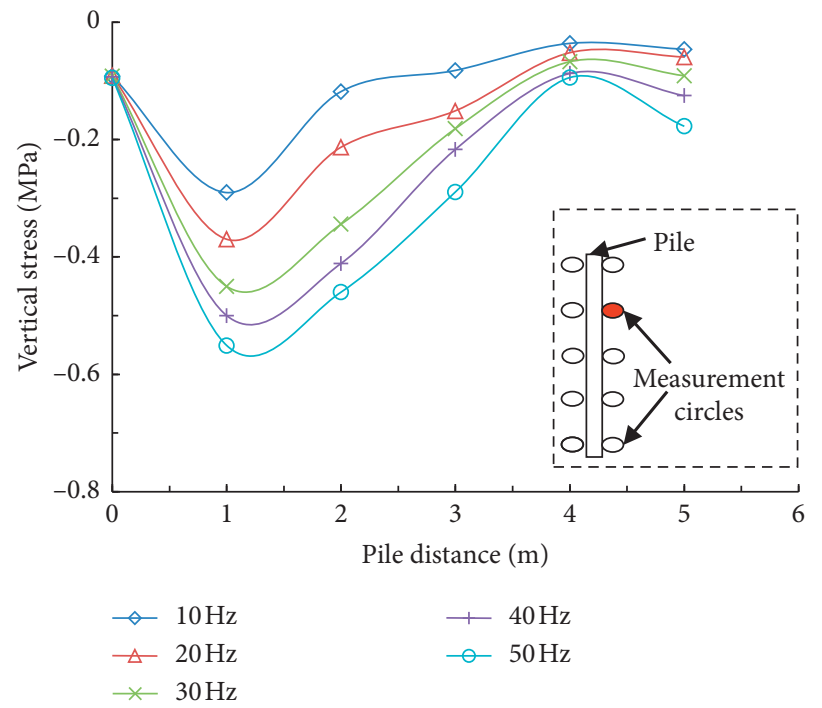

(h)

Figure 7: Continued. 


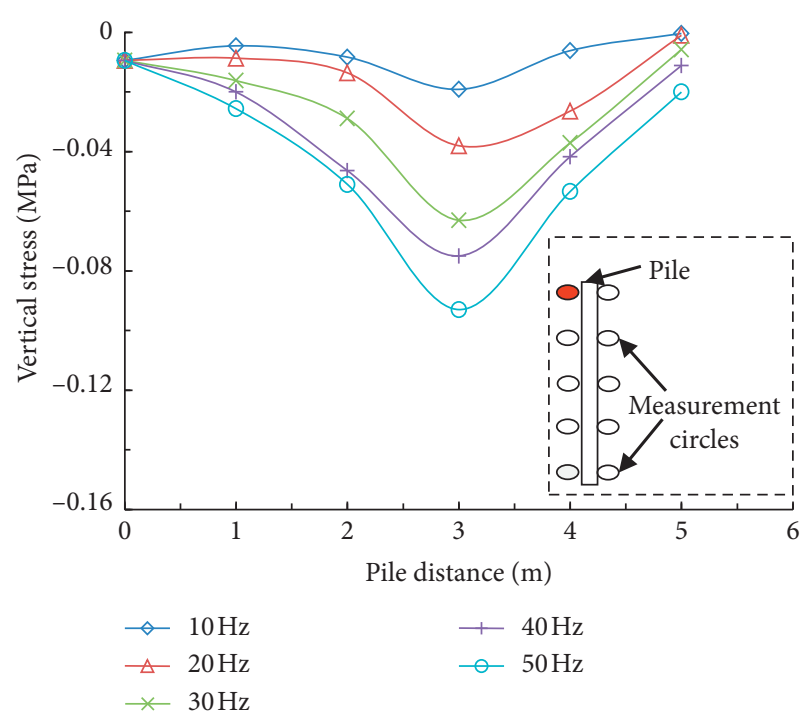

(i)

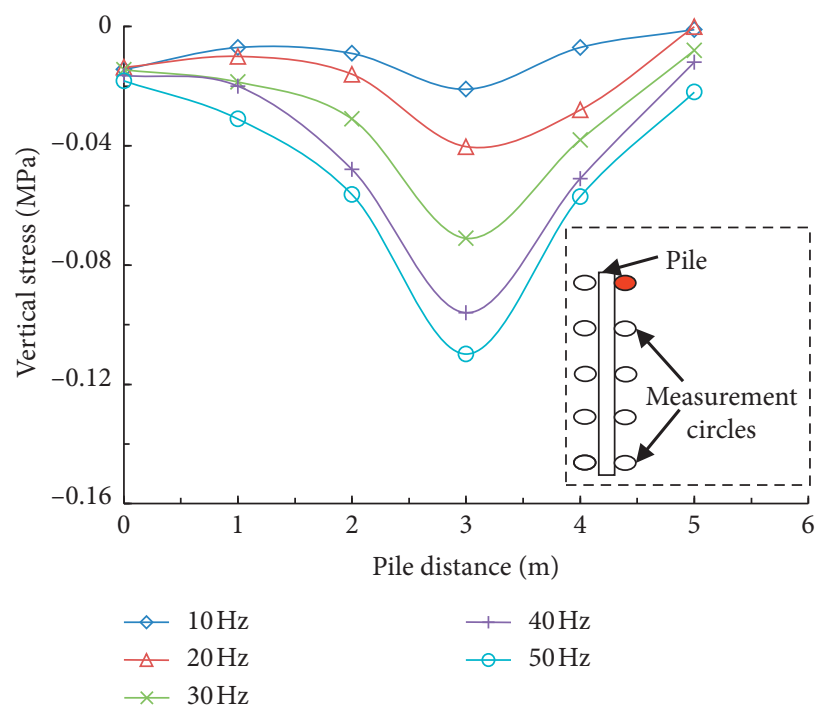

(j)

FIgURE 7: Arrangement of the pile-side vertical measurement circles and a stress distribution diagram.

continuum approach of Novak [63]. Yudina and Verstov [64] analyzed the parameters of the technological process of vibrational driving of the pile and found that the vibrational frequency of the vibratory driver must be at least $30 \mathrm{~Hz}$. In this paper, the distribution of the stress of the soil around the pile has been analyzed with frequencies of $10,20,30,40$, and $50 \mathrm{~Hz}$ in Section 4.1. The regularity of the distribution of the vertical stress during the pulling process was observed, especially when the vibrational frequency was $30 \mathrm{~Hz}$. Based on the above scholars' researches and our study, this paper selects $30 \mathrm{~Hz}$ for further analyzing the bond, coordination number, and porosity distribution of the surrounding soil during the pile-pulling process.

To further evaluate the dynamic properties of the surrounding soil, the distribution of cracks during the pilepulling process is studied. The cohesive force is mainly due to the bond strengths that are assigned between the contacts of particles. When the contact stress, which includes the tensile or compressive stress, exceeds the bond strength, cracks occur; the cracks are represented by deleting the bond between the particles to form a blank area. In the cohesive clay around the pile, it is necessary to analyze the crack distribution of the soil that surrounds the pile during the pulling process so that the crack area will reflect the influence area under the vibrational load. The distributions of bond fractures are analyzed in the surrounding soil during pile pulling with a vibrational frequency of $30 \mathrm{~Hz}$, as shown in Figure 8 .

To evaluate the influence area during the pulling process, the horizontal direction of $12-30 \mathrm{~m}$ and the vertical direction of $12-40 \mathrm{~m}$ of the monitoring area in the model are selected for measuring the bond distribution. As shown in Figure 8, the fracture area, which is represented by the blank area, expands with the increase in the pulling distance of the pile. In the earlier stage, shear failure of the soil occurred, which was accompanied by few fractures. However, with the increase of the pile-pulling distance, the fracture area gradually expands. According to the distribution of the bond fractures, when the pile-pulling distance is $5 \mathrm{~m}$, the major influence zone of the pile pulling on both sides is concentrated within $6 \mathrm{~d}_{\text {pile }}$.

4.3. Coordination Number. In order to further examine the influence of the pile pulling under a dynamic load on the surrounding soil, the coordination number of the particles is studied. The coordination number is defined as the number of contact points between a single soil particle and the surrounding particles, which can serve as an important indicator of the internal structural dynamic properties of the soil during the pulling process. Pulling distances of 1, 2, 3, 4, and $5 \mathrm{~m}$ are considered with the same vibrational frequency of $30 \mathrm{~Hz}$ for evaluating the variation of the particle contacts, as shown in Figure 9.

According to Figure 9, prior to pile pulling, the coordination number is uniform over all particles, with a value of 4.48. As the pulling distance increases, the coordination number of the particles around the pile gradually decreases and the area that corresponds to the reduced coordination number increases. The area of reduced coordination number in the horizontal direction increases with the increase of the pile-pulling distance; hence, the particles around the pile become looser during the pulling process, especially on the pile sides and the pile bottom. The value of the coordination number near the pile side is almost zero as the particles move in a fluid-like state without any rigid contacts [40]. The influence distance on both sides of the pile of $6.0 \mathrm{~m}$ is approximately the same as that in the case of bond fractures (Figure 8). The edge of the area can reflect the shear band in which soil particles around the pile are shearing at the critical state; therefore, the thickness of the shear band increases with the pulling distance.

4.4. Porosity Variation. The porosity reflects the pore distribution in the soil material, which can also reflect the looseness of the soil particles and can be compared with the 


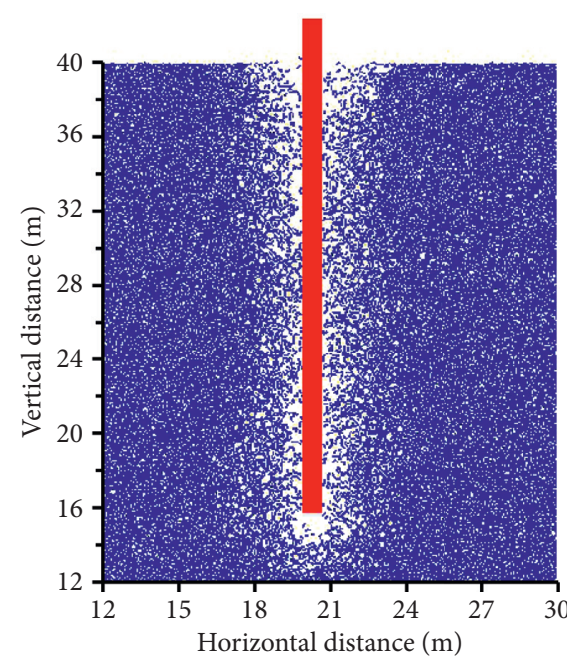

(a)

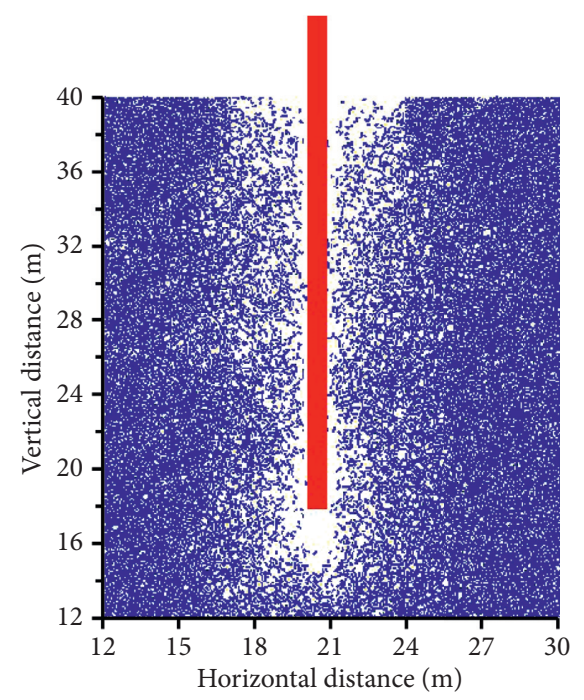

(c)

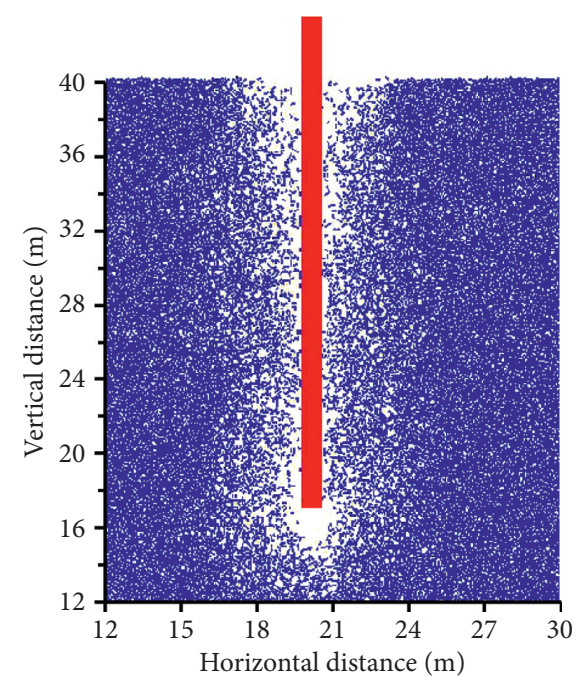

(b)

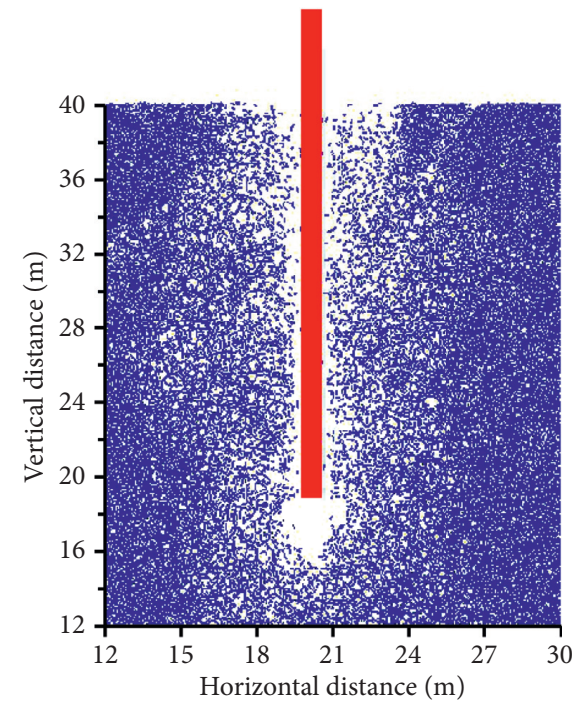

(d)

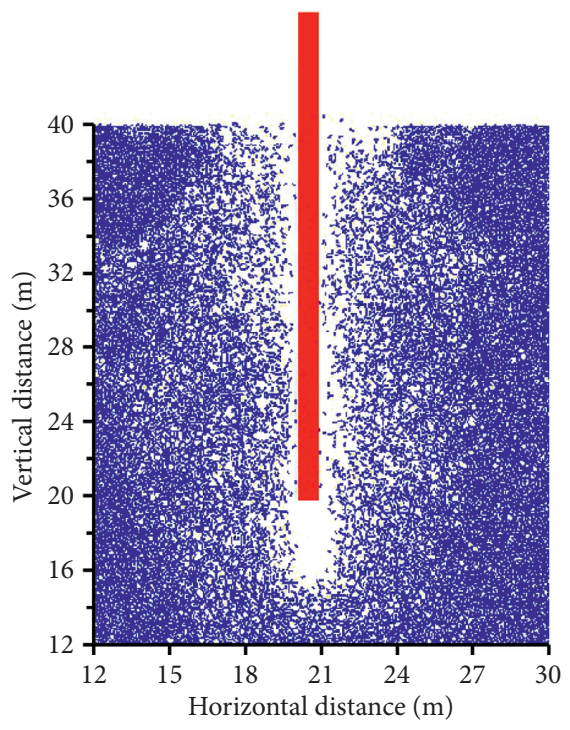

(e)

Figure 8: Particle bond distribution: (a) $1 \mathrm{~m}$; (b) $2 \mathrm{~m}$; (c) $3 \mathrm{~m}$; (d) $4 \mathrm{~m}$; (e) $5 \mathrm{~m}$. 


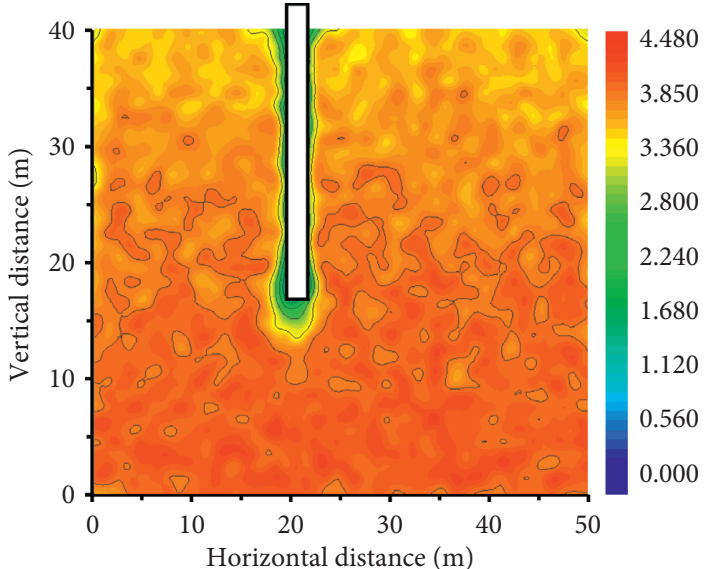

(a)

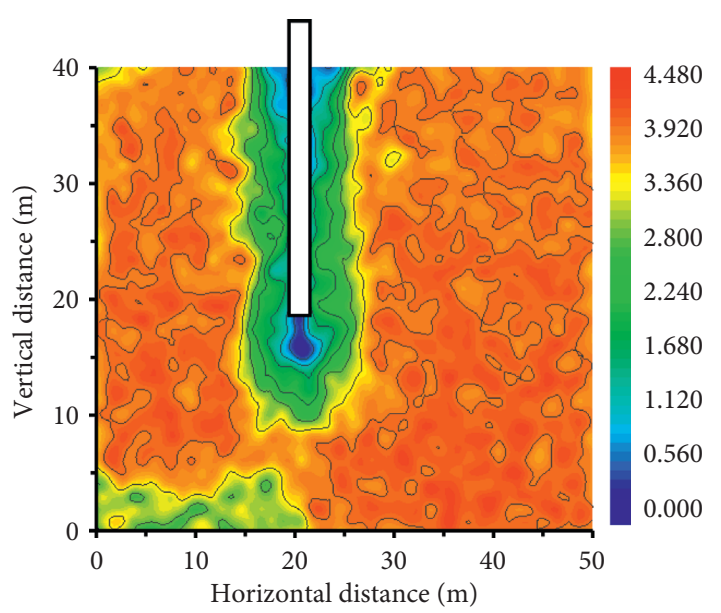

(c)

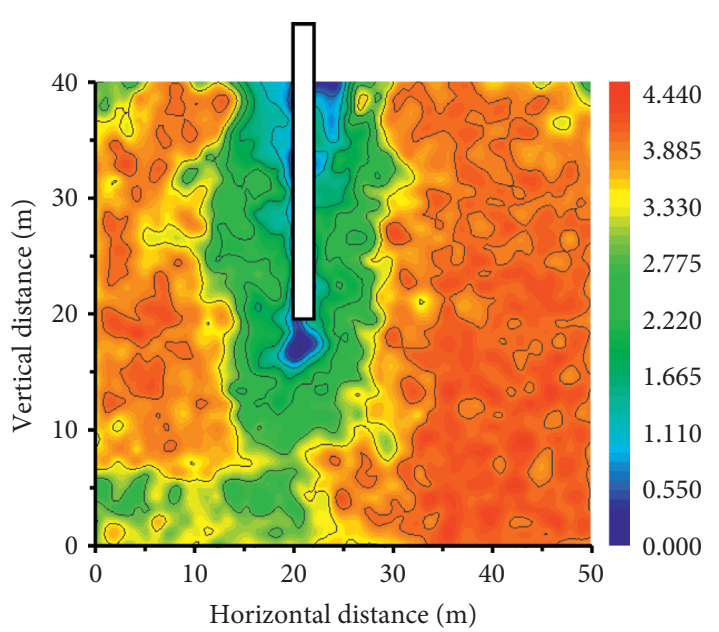

(e)

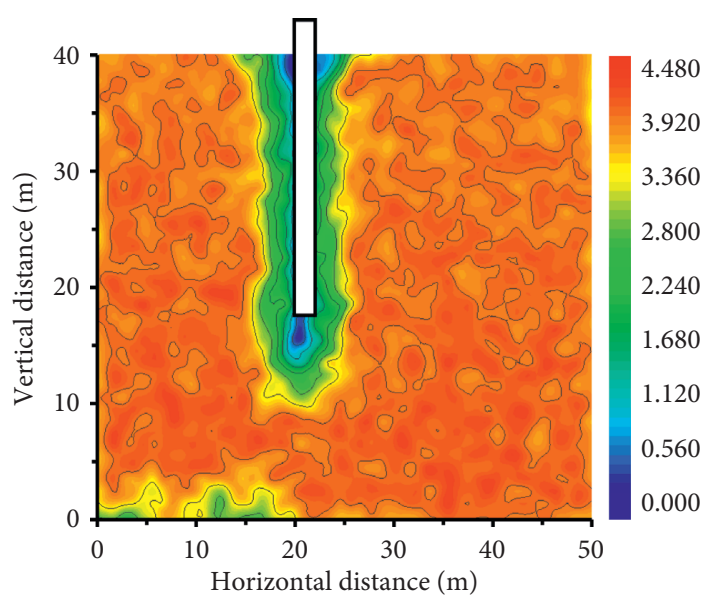

(b)

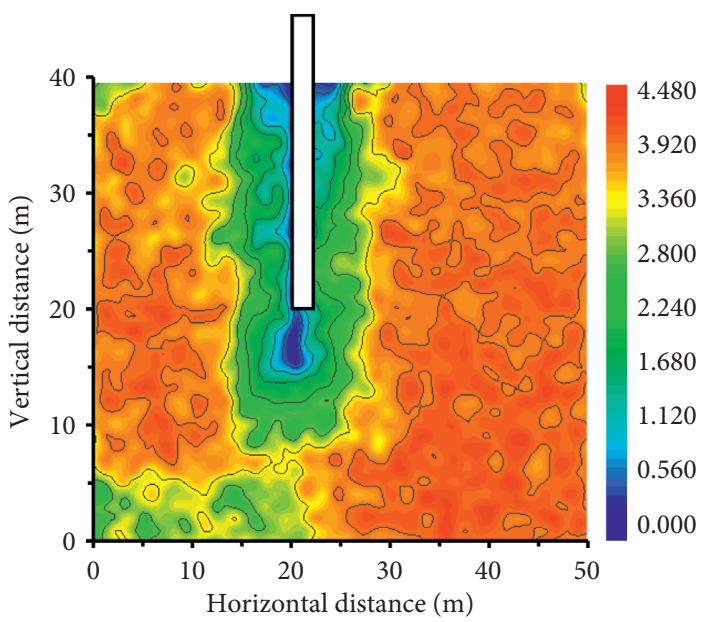

(d)

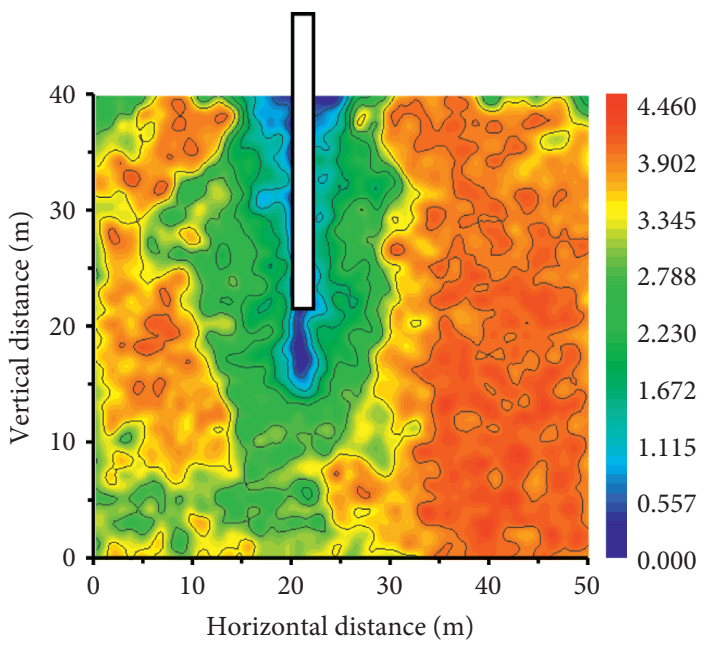

(f)

FIgURE 9: Coordination number distribution: (a) $0 \mathrm{~m}$; (b) $1 \mathrm{~m}$; (c) $2 \mathrm{~m}$; (d) $3 \mathrm{~m}$; (e) $4 \mathrm{~m}$; (f) $5 \mathrm{~m}$.

coordination number during the pulling process. The variation in the porosity under various pulling distances is plotted in Figure 10. The porosity of the granular particles around the pile increases with the pulling distance, and the values of the porosities range from approximately 0.15 prior to pile pulling to 0.26 when the pulling has been completed and the soil around the pile becomes looser. The results are consistent with the results regarding the coordination number (Figure 9). The soil deformation on both sides of the pile displays the bearing capacity mechanism and, 


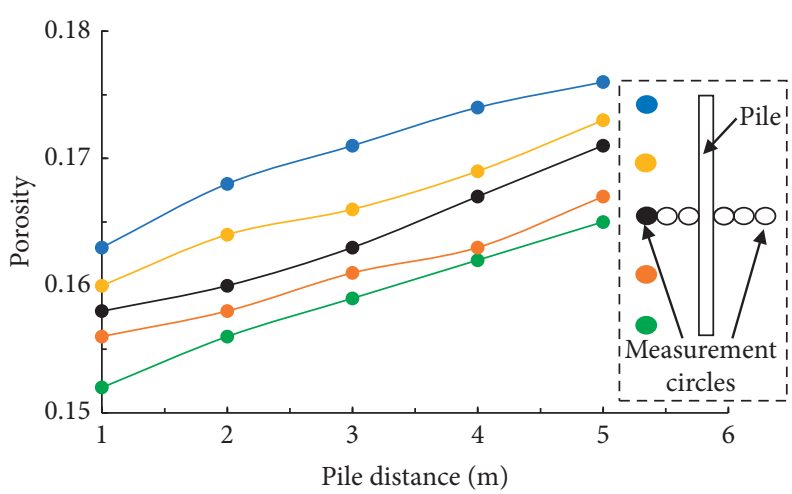

(a)

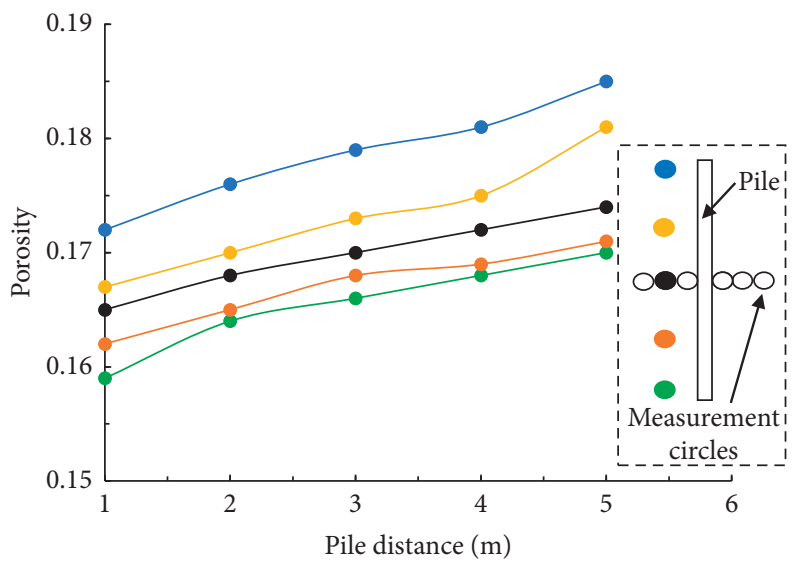

(c)

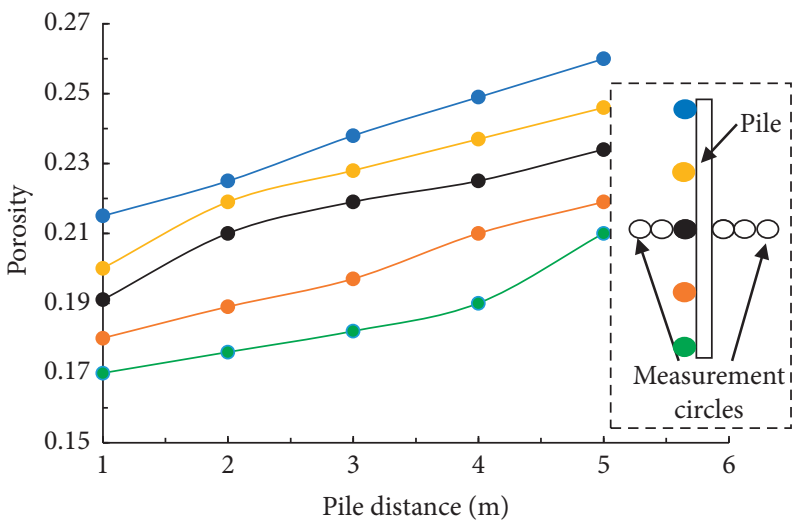

(e)

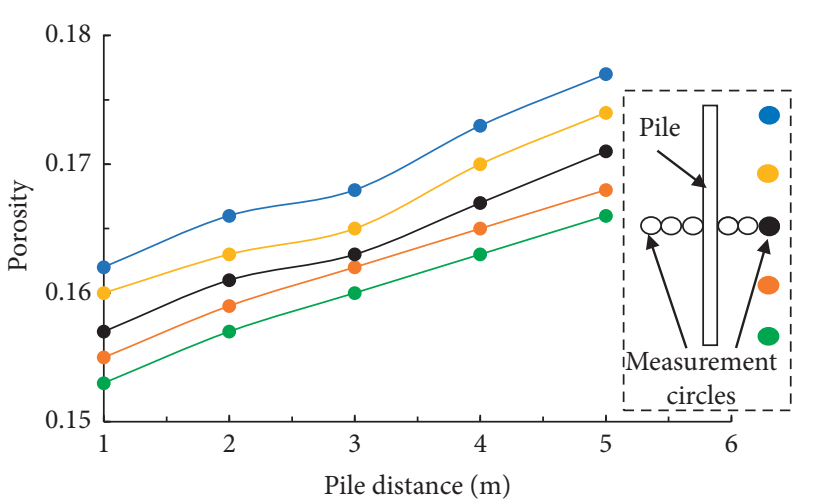

(b)

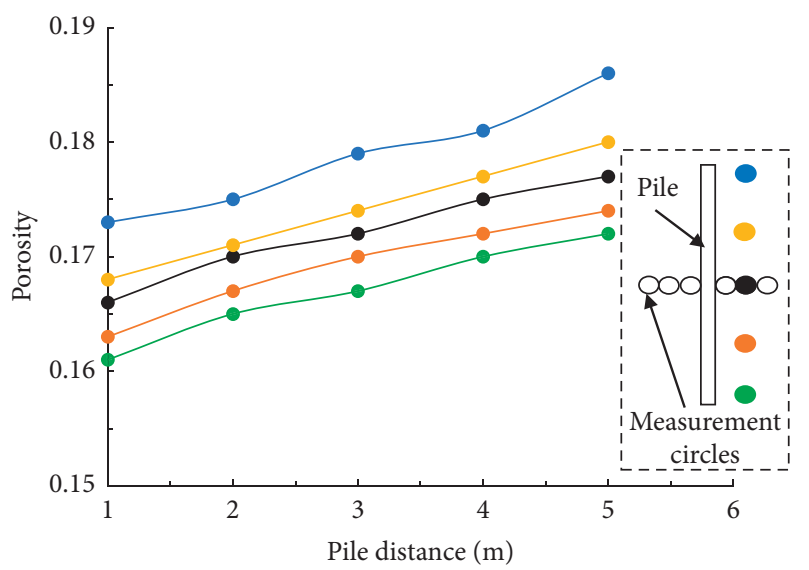

(d)

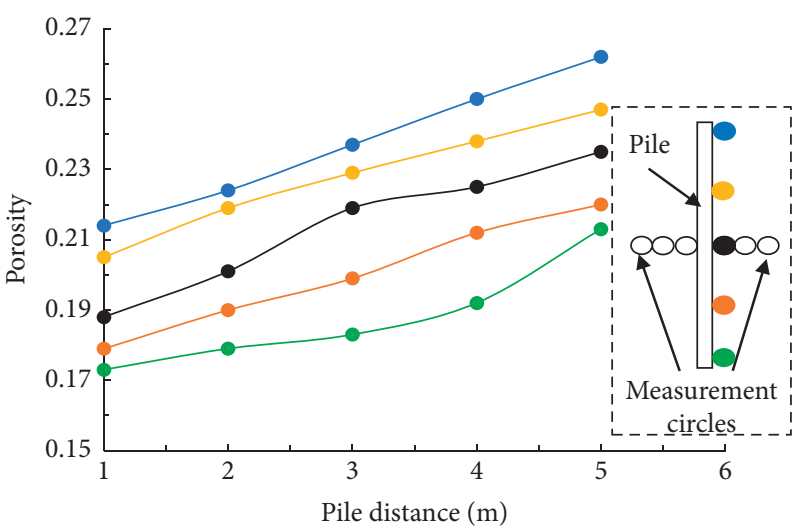

(f)

Figure 10: Porosity distribution: (a) pile left $3 \mathrm{~m}$; (b) pile right $3 \mathrm{~m}$; (c) pile left $2 \mathrm{~m}$; (d) pile right $2 \mathrm{~m}$; (e) pile left $1 \mathrm{~m}$; (f) pile right $1 \mathrm{~m}$ (where the transverse measurement circle distance is $1 \mathrm{~m}$ with a vertical distance of $5 \mathrm{~m}$ ).

subsequently, the shearing failure mechanism. The soil around the pile undergoes large shearing, which promotes the formation of shear bands [29].

With the increase of the pulling distance, the porosity increases and the coordination number decreases, as shown in Figure 11, which is consistent with the research results of Jia et al. [29]. As the porosity increases, the particle contacts gradually fail, which is consistent with the trend of the particle bond distribution (Figure 8).

To thoroughly investigate the influence of pile pulling on the surrounding soil during the pulling process, the motions of two particles were recorded at different positions, as shown in Figure 12.

As illustrated in Figure 12, the particles are relatively dense prior to pile pulling and disperse when the pulling distance is $5 \mathrm{~m}$, which are similar to the experimental results and calculation results of soil particles during vibrational shearing in direct shear tests $[27,66]$. The displacements of the two particles differ along the $X$-direction and the $Y$ direction. The displacement of the green particle in the $Y$ direction is $0.3 \mathrm{~m}$, the displacement of the red particle in the $X$-direction is $0.2 \mathrm{~m}$, and the same regularity of the particle 


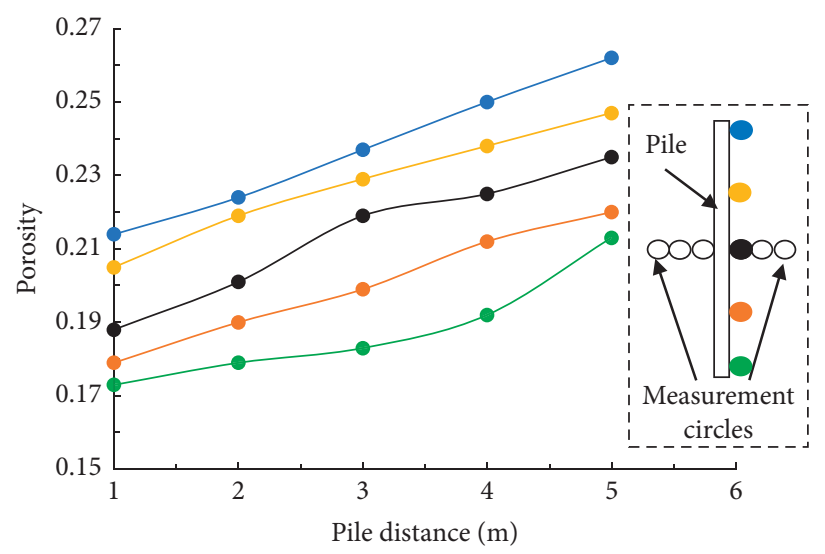

(a)

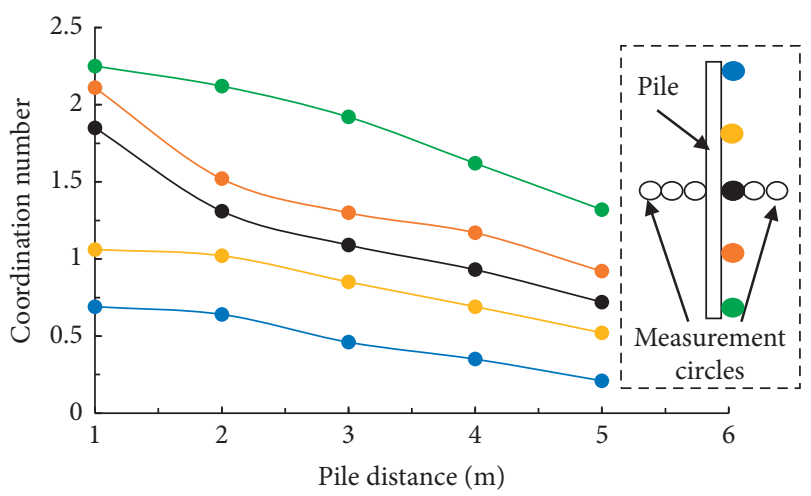

(b)

FIGURE 11: Comparison of the (a) porosity and (b) coordination number at various pile distances.

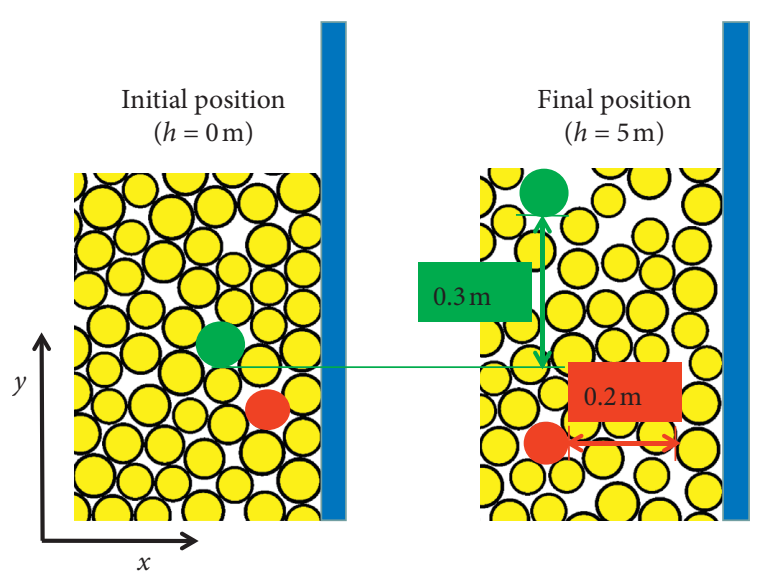

(a)

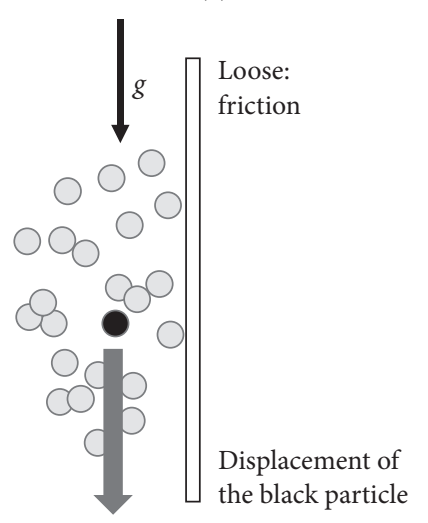

(b)

Figure 12: Variation in the particle displacement before and after pile pulling: (a) calculation results presented in this paper; (b) particle changes from Denies and Holeyman [65].

movement was reported by Denies and Holeyman [65] that the upward movement of the sand grains subjected to vertical vibrations.

Soil particles around the pile move in various directions during the pulling process based on the breakage of the bond fractures. As shown in Figure 13, the bond at the

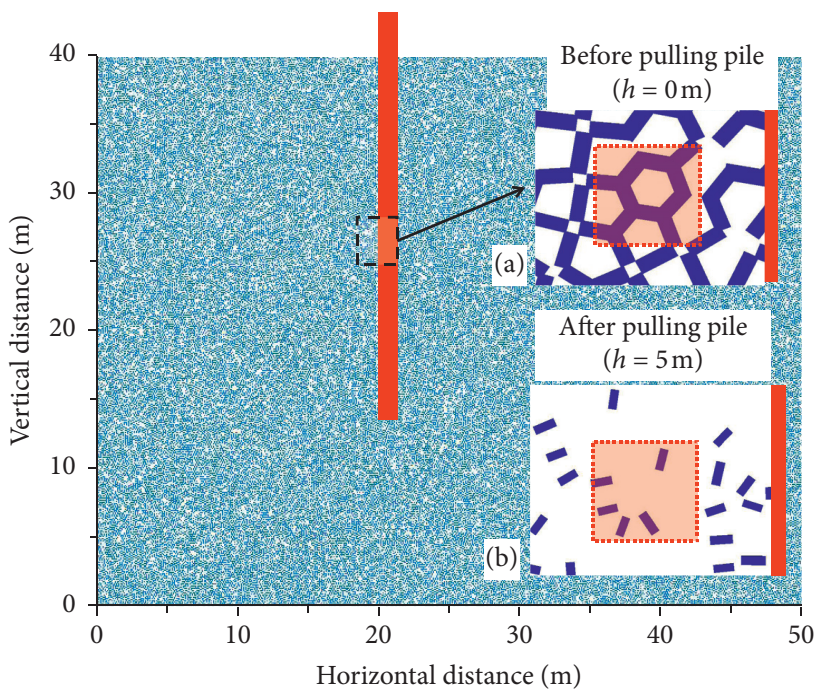

FIgURE 13: Local bond distribution (a) prior to pulling the pile and (b) after pulling the pile.

contact of the particles is measured. Prior to pile pulling, the bonds of the particle are distributed uniformly without any fractures. When the pulling distance is $5 \mathrm{~m}$, the bonds are broken, which leads to particle movement. Therefore, soil deformations under a dynamic frequency occur, which are accompanied by the formation of shear bands [29].

4.5. Velocity and Displacement Fields of the Surroundings. The soil velocity field mainly reflects the status of the soil movement during the pulling process. The velocity changes at various vibrational frequencies $(10,20,30,40$, and $50 \mathrm{~Hz})$ are considered with the same pulling distance of $5 \mathrm{~m}$ to evaluate the frequency effect. The horizontal direction of $12-30 \mathrm{~m}$ and the vertical direction of $12-40 \mathrm{~m}$ in the model are selected, and a cloud map with particle velocities is plotted, as shown in Figure 14.

As shown in Figure 14, prior to pile pulling (Figure 14(a)), the velocities of the particles are uniform with 


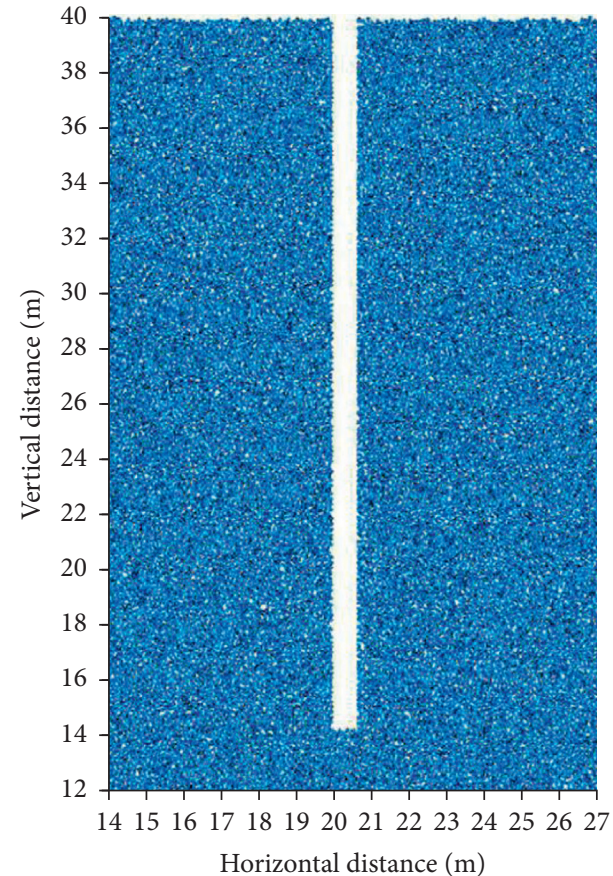

(a)

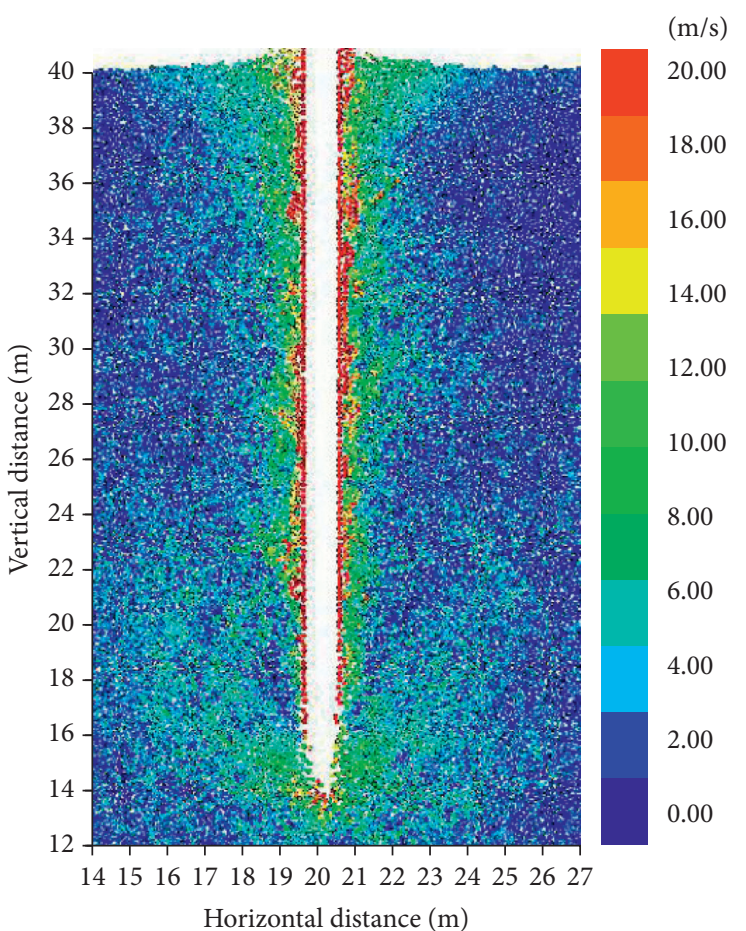

(c)

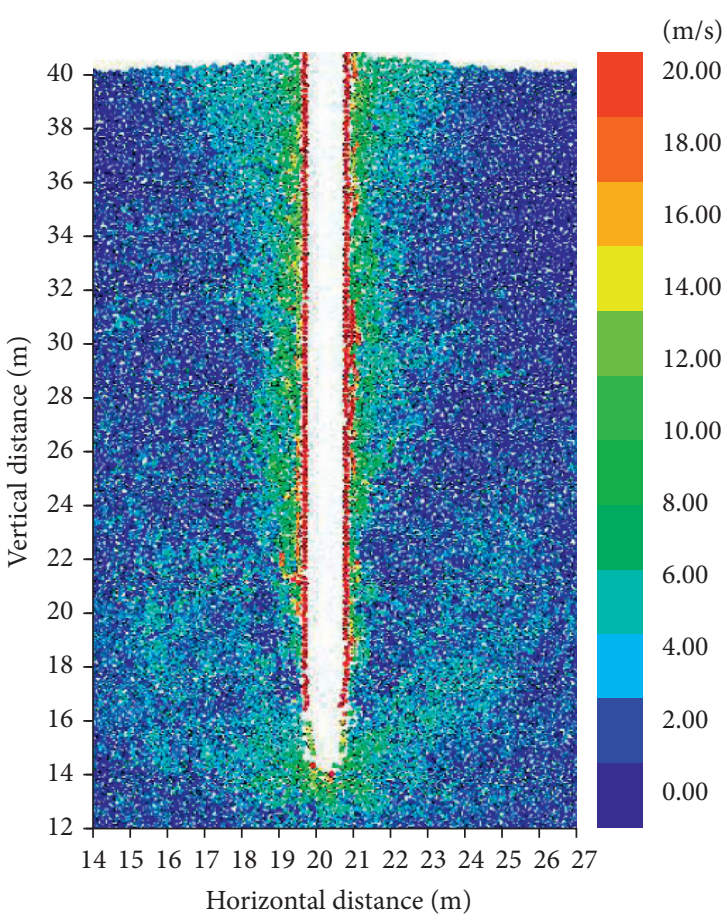

(b)

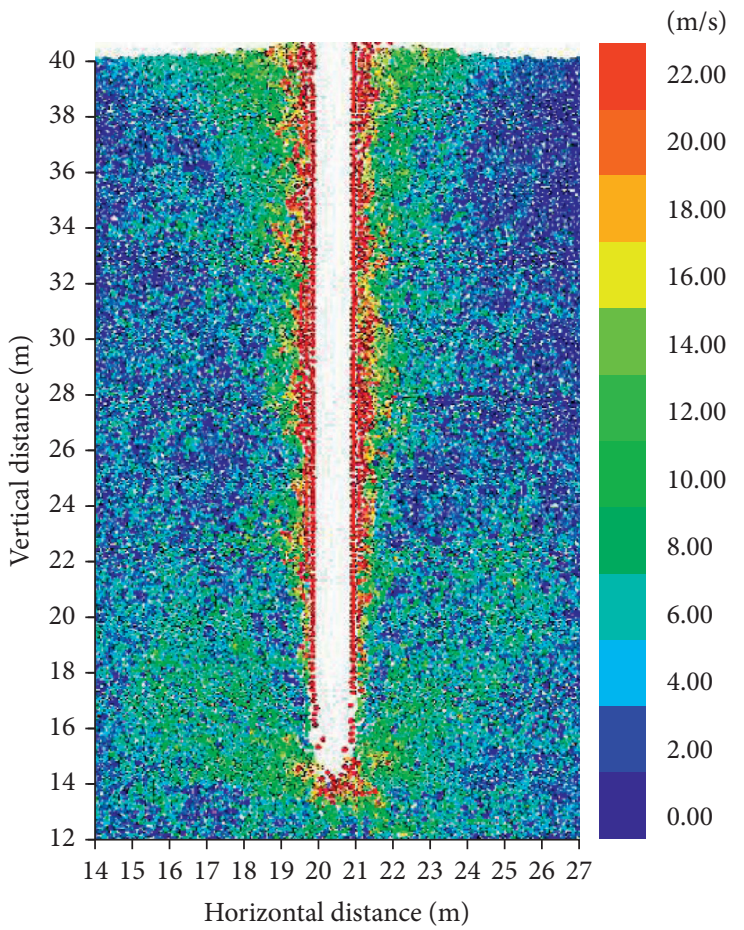

(d)

Figure 14: Continued. 


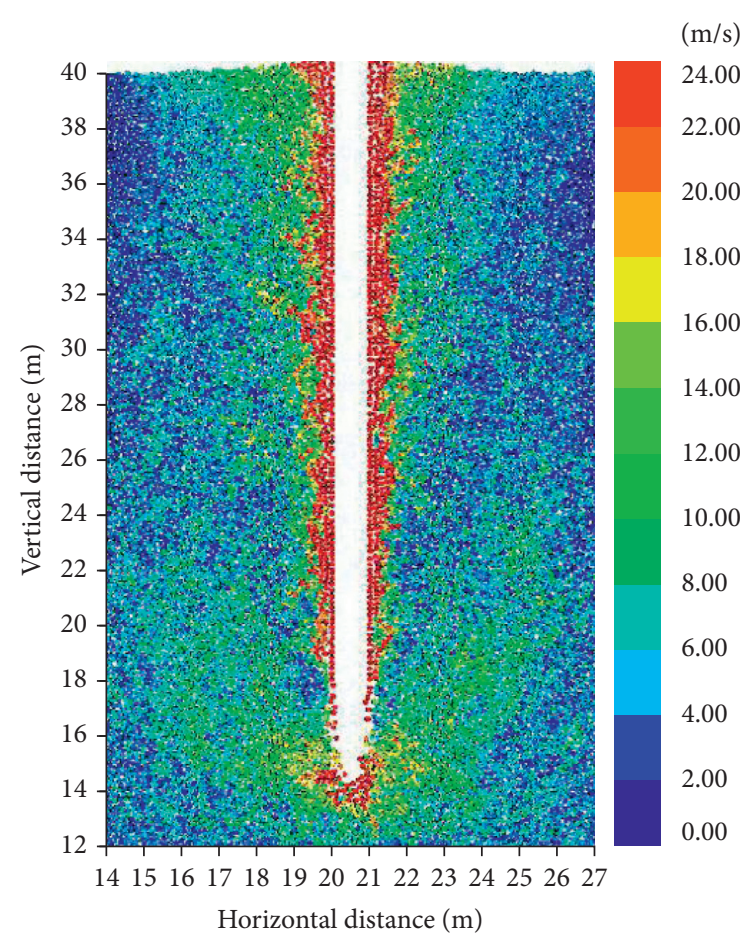

(e)

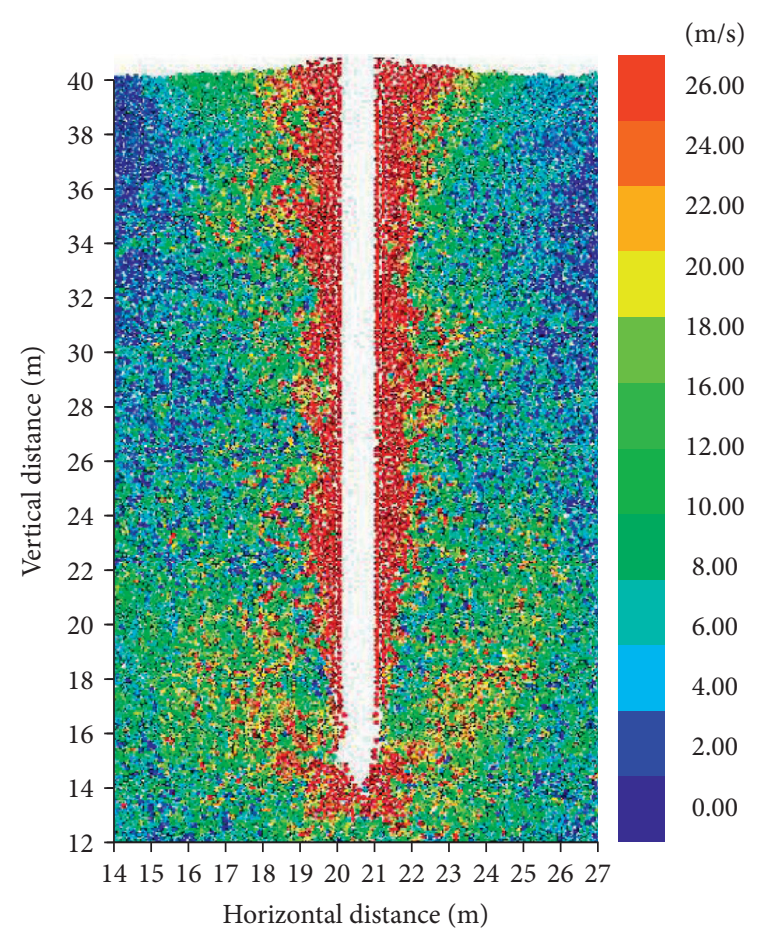

(f)

FIGURe 14: Velocity map of soil particles at various vibrational frequencies: (a) prior to pile pulling; (b) $10 \mathrm{~Hz}$; (c) $20 \mathrm{~Hz}$; (d) $30 \mathrm{~Hz}$; (e) $40 \mathrm{~Hz}$; (f) $50 \mathrm{~Hz}$.

a value of $0 \mathrm{~m} / \mathrm{s}$. As the vibrational frequency increases, the velocities of the particles around the pile gradually increase and the area of increased velocity enlarges during the pulling process, especially on the pile sides and the pile bottom. As shown in Figure 14(b), the velocity of the particles along the pile during the pulling process is in good agreement with the results in Figure 9 when the vibrational frequency is $10 \mathrm{~Hz}$. The values of the velocity variation range from $10 \mathrm{~m} / \mathrm{s}$ to $26 \mathrm{~m} / \mathrm{s}$ when the vibrational frequency is from $10 \mathrm{~Hz}$ to $50 \mathrm{~Hz}$. The edge of the particle motion area corresponds to the shear band in which soil particles around the pile are shearing; consequently, the thickness of the shear band increases with the increase in the vibrational frequency. The results are consistent with the bond distribution (Figure 8).

To further analyze the particle velocity distribution in detail, the displacement and the velocity of particles in the model in the horizontal region of $12-30 \mathrm{~m}$ and the vertical region of 10-30 m are compared, as shown in Figure 15. The particle upward movement accompanies the pile pulling; at the same time, the void is populated after pulling out the pile. In addition, the kinetic energy that is induced by the vibrational load transfer into the surrounding soil is readily measured (Figure 14), and the soil in the affected range expands overall. The displacement map is similar to the experimental results and calculation results that were reported by Hong and Chim [67]. As shown in Figure 15, the angle between the main edge of the movement area of the particles around the pile and the quasistatic part is

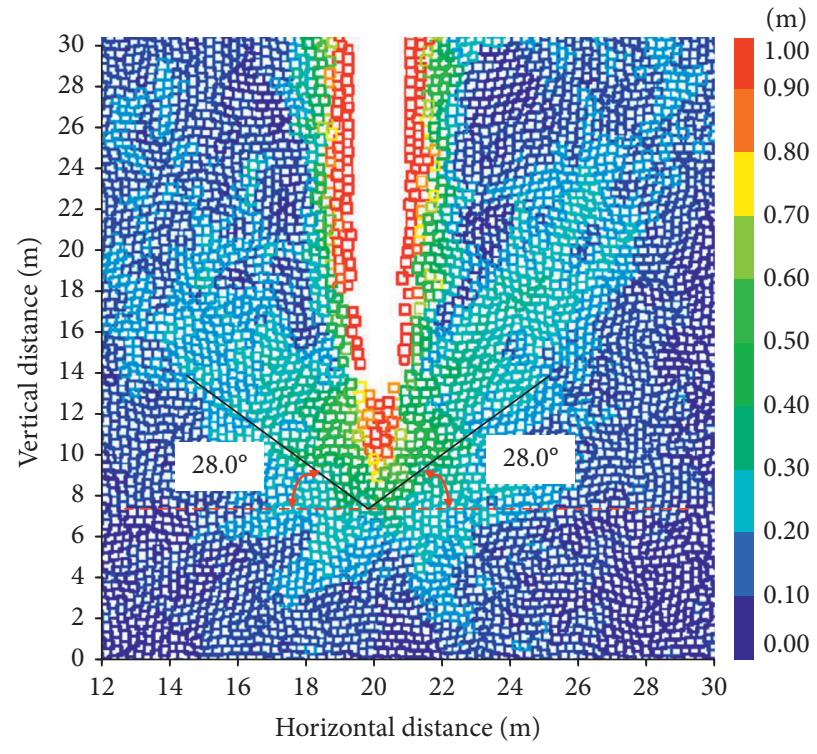

FIgURE 15: Local displacement cloud map and internal friction angle distribution.

approximately $28.0^{\circ}$, which is consistent with the internal friction angle $\left(28.8^{\circ}\right)$ of the surrounding soil. The major influence zone of the pile pulling on both sides is concentrated within $6 \mathrm{~d}_{\text {pile }}$, which is similar to the results that were obtained from the bond distribution, coordination number, and velocity field during the pulling process. 


\section{Conclusions}

In this paper, a discrete element model was proposed for simulating the dynamic characteristics of the surrounding soil during the pile-pulling process and the construction of Jianning Bridge was considered a case study. Five vibrational frequencies $(10,20,30,40$, and $50 \mathrm{~Hz})$ were considered with five pulling distances $(1,2,3,4$, and $5 \mathrm{~m})$ during the pulling process. The stress, bond, coordination number, porosity, and velocity field distribution of the surrounding soil around the pile were analyzed based on the numerical simulation results, and the following conclusions were drawn:

(1) During the pile-pulling process, the states at which soil particles around the pile shear depend on their positions. Particles at the bottom of the pile are shearing prior to the critical state of the shear stress increasing with the shear displacement. The soil reaches the peak shear strength, and the soil particles are separated and reassembled. Then, the rearranged assembly is shearing to attain a higher shear strength, especially when the vibrational frequency is $50 \mathrm{~Hz}$.

(2) Prior to pile pulling, the bonds of the particles are distributed uniformly without any fractures. When the pulling distance is $5 \mathrm{~m}$, the bonds are broken, which is induced by the particle movement. Higher distance leads to larger bond fractures in the surroundings, and the fractures are mainly distributed on both sides and at the bottom of the pile. As the pulling distance increases, the porosity of the surrounding soil increases and the coordination number decreases. According to the dynamic properties of the surrounding soil, the major influence zone of the pile pulling on both sides is concentrated within $6 \mathrm{~d}_{\text {pile }}$.

(3) The area that corresponds to particles with large velocity and displacement increases with the vibrational frequency of the load. The angle between the moved particle area and the relatively static area at the bottom of the pile is close to the internal frictional angle of the surrounding soil. The influence distance of the pile pulling on the surrounding soil in the velocity and displacement fields of the particles is consistent with the results regarding bond fracturing and the coordination number.

\section{Data Availability}

The data used to support the findings of this study are available from the corresponding author upon request.

\section{Conflicts of Interest}

The authors declare that there are no conflicts of interest regarding the publication of this paper.

\section{Acknowledgments}

This project was financially supported by the National Key R\&D Program of China (No. 2017YFC1502503), the State
Key Research Development Program of China (No. 2017YFC0504505), the Anhui Province University Natural Science Major Research Project, China (KJ2019ZD77), the Anhui Province University Natural Science Key Research Project, China (KJ2019A1193 and KJ2017A787), and the Key Program in the Youth Elite Support Plan in Universities of Anhui Province (gxyq2019230), China. The authors wish to express their gratitude for this financial support.

\section{References}

[1] N.-W. Liu, Z.-M. Zhang, Q.-Q. Zhang, and K. Fang, "Destructive field tests on mobilization of end resistance of castin-situ bored piles," Journal of Central South University, vol. 20, no. 4, pp. 1071-1078, 2013.

[2] C. Zhan and J.-H. Yin, "Field static load tests on drilled shaft founded on or socketed into rock," Canadian Geotechnical Journal, vol. 37, no. 6, pp. 1283-1294, 2000.

[3] Q.-Q. Zhang, Z.-M. Zhang, and S.-C. Li, "Investigation into skin friction of bored pile including influence of soil strength at pile base," Marine Georesources \& Geotechnology, vol. 31, no. 1, pp. 1-16, 2013.

[4] A. Al-Mhaidib, "Experimental study on the effect of compressive loads on uplift capacity of model piles in sand," International Journal of Geotechnical Engineering, vol. 6, no. 1, pp. 133-137, 2012.

[5] P. Ni, S. Mangalathu, G. Mei, and Y. Zhao, "Laboratory investigation of pore pressure dissipation in clay around permeable piles," Canadian Geotechnical Journal, vol. 55, no. 9, pp. 1257-1267, 2017.

[6] M. A. Rahman and S. Sengupta, "Uplift capacity of inclined underreamed piles subjected to vertical load," Journal of the Institution of Engineers (India): Series A, vol. 98, no. 4, pp. 533-544, 2017.

[7] M. Xu, P. Ni, G. Mei, and Y. Zhao, "Load-settlement behaviour of bored piles with loose sediments at the pile tip: experimental, numerical and analytical study," Computers and Geotechnics, vol. 102, pp. 92-101, 2018.

[8] Z. Zhang, X. Zhang, S. Sun, and Z. Liang, "A cross-river tunnel excavation considering the water pressure effect based on DEM," European Journal of Environmental and Civil Engineering, pp. 1-17, 2019.

[9] Z. Zhang, X. Zhang, H. Qiu, and M. Daddow, "Dynamic characteristics of track-ballast-silty clay with irregular vibration levels generated by high-speed train based on DEM," Construction and Building Materials, vol. 125, pp. 564-573, 2016.

[10] A. T. Ghalesari, A. Barari, P. F. Amini, and L. B. Ibsen, "The settlement behavior of piled raft interaction in undrained soil," in IACGE 2013: Challenges and Recent Advances in Geotechnical and Seismic Research and Practices, pp. 605-612, ASCE, Reston, VG, USA, 2013.

[11] A. T. Ghalesari and H. Rasouli, "Effect of gravel layer on the behavior of piled raft foundations," in Advances in Soil Dynamics and Foundation Engineering, pp. 373-382, ASCE, Reston, VG, USA, 2014.

[12] A. T. Ghalesari, A. Barari, P. F. Amini, and L. B. Ibsen, "Development of optimum design from static response of pile-raft interaction," Journal of Marine Science and Technology, vol. 20, no. 2, pp. 331-343, 2015.

[13] A. T. Ghalesari and A. Janalizadeh Choobbasti, "Numerical analysis of settlement and bearing behaviour of piled raft in 
Babol clay," European Journal of Environmental and Civil Engineering, vol. 22, no. 8, pp. 978-1003, 2016.

[14] M. Modarresi, H. Rasouli, A. T. Ghalesari, and M. H. Baziar, "Experimental and numerical study of pile-to-pile interaction factor in sandy soil," Procedia Engineering, vol. 161, pp. 1030-1036, 2016.

[15] J. Liu, Z. Guo, N. Zhu et al., "Dynamic response of offshore open-ended pile under lateral cyclic loadings," Journal of Marine Science and Engineering, vol. 7, no. 5, p. 128, 2019.

[16] B. Krishna and N. R. Patra, "Effect of compressive load on oblique pull-out capacity of model piles in sand," Geotechnical and Geological Engineering, vol. 24, no. 3, pp. 593-614, 2006.

[17] A. S. Azizkandi, A. Kashkooli, and M. H. Baziar, "Prediction of uplift pile displacement based on cone penetration tests (CPT)," Geotechnical and Geological Engineering, vol. 32, no. 4, pp. 1043-1052, 2014.

[18] S. M. Rangari, D. Choudhury, and D. M. Dewaikar, "Seismic uplift capacity of shallow horizontal strip anchor under oblique load using pseudo-dynamic approach," Soils and Foundations, vol. 53, no. 5, pp. 692-707, 2013.

[19] B. C. Chattopadhyay and P. J. Pise, "Uplift capacity of piles in sand," Journal of Geotechnical Engineering, vol. 112, no. 9, pp. 888-904, 1986.

[20] R. Nazir, H. Moayedi, A. Pratikso, and M. Mosallanezhad, "The uplift load capacity of an enlarged base pier embedded in dry sand," Arabian Journal of Geosciences, vol. 8, no. 9, pp. 7285-7296, 2015.

[21] H. Moayedi, R. Nazir, M. Mosallanezhad, R. B. M. Noor, and M. Khalilpour, "Lateral deflection of piles in a multilayer soil medium. Case study: the terengganu seaside platform," Measurement, vol. 123, pp. 185-192, 2018.

[22] A. Tombari, M. H. El Naggar, and F. Dezi, "Impact of ground motion duration and soil non-linearity on the seismic performance of single piles," Soil Dynamics and Earthquake Engineering, vol. 100, pp. 72-87, 2017.

[23] A. Carstensen, T. Pucker, and J. Grabe, "Numerical model to predict the displacement of piles under cyclic lateral loading using a new hypoplastic spring element," Computers and Geotechnics, vol. 101, pp. 217-223, 2018.

[24] C. Thornton, "Numerical simulations of deviatoric shear deformation of granular media," Géotechnique, vol. 50, no. 1, pp. 43-53, 2000.

[25] Y. Cui, C. E. Choi, L. H. D. Liu, and C. W. W. Ng, "Effects of particle size of mono-disperse granular flows impacting a rigid barrier," Natural Hazards, vol. 91, no. 3, pp. 1179-1201, 2018.

[26] W. Chen, X. Huang, and X. Liu, "Particle flow simulation of effect of pushing against soil of static driven piles," in Proceedings of the 5th International Conference on Information Engineering for Mechanics and Materials, Atlantis Press, Huhhot, Mongolia, July 2015.

[27] Z. Zhang, Y. Cui, D. H. Chan, and K. A. Taslagyan, "DEM simulation of shear vibrational fluidization of granular material,” Granular Matter, vol. 20, no. 4, p. 71, 2018.

[28] Z.-Y. Ma, F.-N. Dang, and H.-J. Liao, "Numerical study of the dynamic compaction of gravel soil ground using the discrete element method," Granular Matter, vol. 16, no. 6, pp. 881-889, 2014.

[29] M. Jia, Y. Yang, B. Liu, and S. Wu, "PFC/FLAC coupled simulation of dynamic compaction in granular soils," Granular Matter, vol. 20, no. 4, p. 76, 2018.

[30] J. Fu, N. Duan, L. Cui, and N. Zhu, "DEM investigation of installation responses of jacked open-ended piles," Acta Geotechnica, vol. 14, pp. 1-15, 2019.
[31] J. Liu, Z. Guo, and B. Han, "Load transfer of offshore openended pipe piles considering the effect of soil plugging," Journal of Marine Science and Engineering, vol. 7, no. 9, p. 313, 2019.

[32] P. A. Cundall and O. D. L. Strack, "A discrete numerical model for granular assemblies," Géotechnique, vol. 29, no. 1, pp. 47-65, 1979.

[33] Itasca Consulting Group Inc, PFC 5.0 Documentation, ICG, Minneapolis, MN, USA, 2015.

[34] Y. Cui, D. Chan, and A. Nouri, "Coupling of solid deformation and pore pressure for undrained deformation-a discrete element method approach," International Journal for Numerical and Analytical Methods in Geomechanics, vol. 41, no. 18, pp. 1943-1961, 2017.

[35] Y. Cui, A. Nouri, D. Chan, and E. Rahmati, "A new approach to DEM simulation of sand production," Journal of Petroleum Science and Engineering, vol. 147, pp. 56-67, 2016.

[36] Y. Cui, Y. Jiang, and C. Guo, "Investigation of the initiation of shallow failure in widely graded loose soil slopes considering interstitial flow and surface runoff," Landslides, vol. 16, no. 4, pp. 815-828, 2019.

[37] Y.-F. Cui, X.-J. Zhou, and C.-X. Guo, "Experimental study on the moving characteristics of fine grains in wide grading unconsolidated soil under heavy rainfall," Journal of Mountain Science, vol. 14, no. 3, pp. 417-431, 2017.

[38] C. Guo and Y. Cui, "Pore structure characteristics of debris flow source material in the Wenchuan earthquake area," Engineering Geology, vol. 267, Article ID 105499, 2020.

[39] M. Saadat and A. Taheri, "A cohesive discrete element based approach to characterizing the shear behavior of cohesive soil and clay-infilled rock joints," Computers and Geotechnics, vol. 114, p. 103109, 2019.

[40] Z.-H. Zhang, X.-D. Zhang, Y. Tang, and Y.-F. Cui, "Discrete element analysis of a cross-river tunnel under random vibration levels induced by trains operating during the flood season," Journal of Zhejiang University-Science A, vol. 19, no. 5, pp. 346-366, 2018.

[41] Z. Zhang, X. Zhang, Y. Cui, and H. Qiu, "Discrete element modeling of a cross-river tunnel under subway train operation during peak and off-peak periods," Arabian Journal of Geosciences, vol. 12, no. 3, p. 102, 2019.

[42] Q. Yang, K. Cheng, Y. Wang, and M. Ahmad, "Improvement of semi-resolved CFD-DEM model for seepage-induced fineparticle migration: eliminate limitation on mesh refinement," Computers and Geotechnics, vol. 110, pp. 1-18, 2019.

[43] E. Badakhshan, A. Noorzad, A. Bouazza, Y. F. Dafalias, S. Zameni, and L. King, "Load recovery mechanism of arching within piled embankments using discrete element method and small scale tests," Powder Technology, vol. 359, pp. 59-75, 2020.

[44] X. Zhang, Z. Li, Z. Zhang, and Y. Li, "Discrete element analysis of the rheological characteristics of self-compacting concrete with irregularly shaped aggregate," Arabian Journal of Geosciences, vol. 11, no. 19, p. 597, 2018.

[45] D. L. Zhang and Z. Y. Sun, "An active control waterproof and drainage system of subsea tunnels and its design method," Chinese Journal of Rock Mechanics and Engineering, vol. 38, no. 1, pp. 1-17, 2019.

[46] G. Li, "Some problems about principle of effective stress," Chinese Journal of Geotechnical Engineering, vol. 33, no. 2, pp. 315-320, 2011.

[47] L. Song, X. Kang, and G. Mei, "Buoyancy force on shallow foundations in clayey soil: an experimental investigation 
based on the "half interval search"," Ocean Engineering, vol. 129, pp. 637-641, 2017.

[48] P. Ni, X. Kang, L. Song, G. Mei, and Y. Zhao, "Model tests of buoyant force on underground structures," Journal of Testing and Evaluation, vol. 47, no. 2, pp. 1216-1235, 2019.

[49] C. Kang, Modelling entrainment in debris fow analysis for dry granular material, Univer Sity of Alberta, Ph.D. thesis, Alberta, Canada, 2016.

[50] N. H. T. Nguyen, H. H. Bui, J. Kodikara, S. Arooran, and F. Darve, "A discrete element modelling approach for fatigue damage growth in cemented materials," International Journal of Plasticity, vol. 112, pp. 68-88, 2019.

[51] ASTM D3080-04, Standard Test Method for Direct Shear Test of Soils under Consolidated Drained Conditions, ASTM International, West Conshohocken, PA, USA, 2011.

[52] J. F. Lu, C. W. Zhang, and P. Jian, "Meso-structure parameters of discrete element method of sand pebble surrounding rock particles in different dense degrees," in Proceedings of the International Conference on Discrete Element Methods, pp. 871-879, Springer, Wuhan, China, August 2016.

[53] X. Gu, L. Lu, and J. Qian, "Discrete element modeling of the effect of particle size distribution on the small strain stiffness of granular soils," Particuology, vol. 32, pp. 21-29, 2017.

[54] Y. X. Zhan, H. L. Yao, Q. P. Dong, and D. P. He, "Study of process of open-ended pipe pile driven into sand soil by particle flow simulation," Rock and Soil Mechanics, vol. 34, no. 1, pp. 283-289, 2013.

[55] V. Sadrmanesh and Y. Chen, "Simulation of tensile behavior of plant fibers using the discrete element method (DEM)," Composites Part A: Applied Science and Manufacturing, vol. 114, pp. 196-203, 2018.

[56] CEN (European Committee for Standardization), Metallic Materials-Tensile Testing-Part 1: Method of Test at Ambient Temperature, CEN (European Committee for Standardization), Brussels, Belgium, 2009.

[57] China First Metallurgical Group Co., Ltd., Jianning Bridge Pile Pulling Construction Plan, China First Metallurgical Group Co., Ltd., Wuhan, China, 2018.

[58] W. R. Liu, X. Wang, and C. M. Li, "Numerical study of damage evolution law of coal mine roadway by particle flow code (PFC) model," Geotechnical and Geological Engineering, vol. 37, pp. 1-9, 2019.

[59] S. Henke and J. Grabe, "Numerical investigation of soil plugging inside open-ended piles with respect to the installation method," Acta Geotechnica, vol. 3, no. 3, pp. 215-223, 2008.

[60] T. E. Adejumo and I. L. Boiko, "Pile foundation and installation methods in Nigeria," Electronic Journal of Geotechnical Engineering, vol. 17, pp. 2613-2621, 2012.

[61] V. Kitovas, G. Stelmokaitis, and V. Doroševas, "Investigation of vibrations influence on clay soil parameters," Journal of Sustainable Architecture and Civil Engineering, vol. 4, pp. 60-67, 2016.

[62] S. S. Choudhary, S. Biswas, and B. Manna, "Dynamic characteristics of a 3-pile group under vertical vibration," in Advances in Soil Dynamics and Foundation Engineering, pp. 363-372, ASCE, Reston, VG, USA, 2014.

[63] M. Novak and H. Mitwally, "Random response of offshore towers with pile-soil-pile interaction," Journal of Offshore Mechanics and Arctic Engineering, vol. 112, no. 1, pp. 35-41, 1990.

[64] A. Yudina and V. Verstov, "Control and reduction of dynamic disturbances during vibratory driving of sheet pile into soil," Soil Mechanics \& Foundation Engineering, vol. 54, no. 1, 2017.
[65] N. Denies and A. Holeyman, "Shear strength degradation of vibrated dry sand," Soil Dynamics and Earthquake Engineering, vol. 95, pp. 106-117, 2017.

[66] K. Hashemnia and S. Pourandi, "Study the effect of vibration frequency and amplitude on the quality of fluidization of a vibrated granular flow using discrete element method," Powder Technology, vol. 327, pp. 335-345, 2018.

[67] W.-P. Hong and N. Chim, "Prediction of uplift capacity of a micropile embedded in soil," KSCE Journal of Civil Engineering, vol. 19, no. 1, pp. 116-126, 2015. 